Sharif University of Technology
Scientia Iranica
Transactions E: Industrial Engineering
hCIENTIA

\title{
Sustainability assessment of supply chains by inverse network dynamic data envelopment analysis
}

\author{
M. Kalantary ${ }^{\mathrm{a}}$, R. Farzipoor Saen ${ }^{\mathrm{b}}$, and A. Toloie Eshlaghy ${ }^{\mathrm{a}, *}$ \\ a. Department of Industrial Management, Science and Research Branch, Islamic Azad University, Tehran, Iran. \\ b. Department of Industrial Management, Karaj Branch, Islamic Azad University, Karaj, Iran. \\ Received 10 February 2017; received in revised form 10 August 2017; accepted 25 December 2017
}

\author{
KEYWORDS \\ Sustainable Supply \\ Chain Management \\ (SSCM); \\ Data Envelopment \\ Analysis (DEA); \\ Range Adjusted \\ Measure (RAM); \\ Inverse data \\ envelopment analysis; \\ Network DEA; \\ Dynamic DEA.
}

\begin{abstract}
This paper focuses on assessing sustainability of supply chains. This paper, at first, proposes network dynamic Range Adjusted Measure (RAM) model. Then, an inverse version of network dynamic RAM model is proposed. The proposed inverse network dynamic Data Envelopment Analysis (DEA) model changes both inputs and outputs of Decision-Making Units (DMUs) so that existing efficiency scores of DMUs remain unchanged. We change inputs and outputs without any modification in efficiency score of DMU under evaluation, while inputs and outputs may have a large range. A case study shows the efficacy of the proposed model.
\end{abstract}

(C) 2018 Sharif University of Technology. All rights reserved.

\section{Introduction}

Nowadays, our earth encounters a number of difficulties such as air pollution, little or lack of water resources, energy inefficiency, destruction of forests, etc. For this reason, supply chains should be responsible for environmental issues. Mentzer et al. [1] defined Supply Chain Management (SCM) as "the systemic, strategic coordination of traditional business functions and the tactics across these business functions within a particular company and across businesses within the supply chain, for the purposes of improving the longterm performance of the individual companies and the supply chain as a whole". Drumwright [2] and Murphy et al. [3] introduced Sustainable Supply Chain

\footnotetext{
*. Corresponding author.

E-mail addresses: majidkalantary.pm@gmail.com (M. Kalantary); farzipour@yahoo.com (R. Farzipoor Saen); toloie@gmail.com (A. Toloie Eshlaghy).
}

doi: $10.24200 /$ sci. 2017.20017
Management (SSCM). Carter and Rogers [4] defined SSCM as "the strategic, transparent integration and achievement of an organization's social, environmental, and economic goals in the systemic coordination of key inter-organizational business processes for improving the long-term economic performance of the individual company and its supply chains". At the moment, sustainability considerations are not just a symbolic action; however, they are reactive to pressures of Non-Governmental Organizations (NGOs), media, and green political parties [5]. Many firms have established tough evaluations for suppliers in their supply chain to ensure that the sustainability considerations are addressed seriously [6-8].

Charnes et al. [9] proposed Data Envelopment Analysis (DEA). DEA is a proper tool for assessing relative efficiency of supply chains [10]. In classical DEA models, Decision-Making Units (DMUs) are considered as a black box. Lewis and Sexton [11] proposed a network DEA model to deal with divisions in each DMU. In addition, most of other traditional DEA models measure efficiency score just in a specific 
period. For the first time, Färe and Grosskopf [12] proposed dynamic DEA model. Tone and Tsutsui [13] considered the network DEA model dynamically and, then, proposed a network dynamic DEA model based on Slacks-Based Measure (SBM) approach. They named efficiencies of each period and each division as "term" and "divisional" efficiencies, respectively.

This paper proposes input-oriented Range Adjusted Measure (RAM) model and clarifies the reason for using this model. Then, an inverse model of network dynamic input/output-oriented RAM is proposed. To the best of our knowledge, the inverse RAM model with network and dynamic structure has not been proposed so far. This paper has the following contributions: the following topics are proposed in this paper for the first time:

- Input/output-oriented RAM model with dynamic and network structure is developed;

- The inverse model of dynamic-network input/ output-oriented RAM model is developed;

- Both inputs and outputs of Decision-Making Units (DMUs) can be changed in our inverse DEA model;

- The proposed model is applied to the assessment of the sustainability of supply chains;

- To demonstrate the applicability of our model, a case study is given.

The main objective of this paper is to develop network-dynamic input-oriented RAM model and its inverse for assessing sustainability of supply chains.

The structure of this paper is organized as follows. Literature review is presented in Section 2. The proposed models are given in Section 3. A case study is given in Section 4. Managerial implications and conclusions are explained in Sections 5 and 6 , respectively.

\section{Literature review}

\subsection{Sustainable SCM}

As mentioned earlier, environmental and social responsibilities in SCM started to receive attention in 1994 and continued through researches such as greening supply chain [14], greening product $[15,16]$, and greening supply chain from product design to end user $[17,18]$.

Liu et al. [19] focused on eco-friendly competition between substitutable products and retail stores. They found that eco-friendly manufacturers earned more profits because of customers' environmental awareness. Zhang et al. [20] studied impact of customers' environmental awareness on companies. Ghosh and Shah [21] discussed greening costs and impact of greening sensitivity of customers on profit. Xie [22] studied the role of policy-makers in energy saving.
Assessing sustainability of supply chains is an important topic. Genovese et al. [23] proposed an environmentally extended Multi-Regional Input-Output (MRIO) hybrid model and Life Cycle Assessment (LCA) that can be used for emissions assessment of supply chains. They evaluated supply chains based on emissions. Su et al. [24] addressed improving sustainability of supply chain management in situations with incomplete information. They proposed a hierarchical grey-DEMATEL approach. Dubey et al. [25] focused on dynamic nature of SSCM. They addressed both quantitative and qualitative approaches. Kumar et al. [26] assessed suppliers based on SSCM criteria. They applied fuzzy multi-criteria decisionmaking model. Azadi et al. [27] developed a fuzzy model for assessing sustainability of suppliers in terms of economic, environmental, and social factors. $\mathrm{Li}$ and Cui [28] proposed network range adjusted measure model to evaluate sustainability of supply chains. Table 1 summarizes previous researches on sustainable SCM criteria and used techniques.

This paper proposes inverse network dynamic input-oriented RAM model to assess sustainability of supply chains as well as given economic, environmental, and social criteria.

\subsection{Data Envelopment Analysis (DEA)}

\subsubsection{Inverse $D E A$}

Wei et al. [37], for the first time, proposed inverse DEA model. The main purpose of the inverse DEA model is to analyze sensitivity of a DEA model to changes in inputs/outputs of $\mathrm{DMU}_{o}$ (DMU under evaluation) without any change in $\mathrm{DMU}_{o}$ efficiency score. In other words, after changes in inputs/outputs, Production Possibility Set (PPS) changes; however, efficient frontier should not be changed dramatically [38].

Yan et al. [38] introduced an inverse DEA model for resource planning, given decision-makers' preferences. Jahanshahloo et al. [39] developed the inverse model of Yan et al. [38] and presented inverse DEA model to estimate outputs, given changes in inputs. Jahanshahloo et al. [40] developed an inverse DEA model to estimate inputs, given outputs increase and improvements in efficiency score. Furthermore, they estimated maximum reduction in inputs without changing efficiency scores. Jahanshahloo et al. [41] ran a sensitivity analysis by inverse DEA model. They determined upper and lower bounds for inputs and outputs by two multi-objective linear programming problems and converted multi-objective linear programme to a linear program. Jahanshahloo et al. [42] addressed intertemporal dependency among efficiencies of a $\mathrm{DMU}_{o}$ in multiple periods. They proposed inverse dynamic DEA model. Furthermore, they introduced a periodic weak Pareto solution in multiple-objective linear programming. Lertworasirikul et al. [43] proposed inverse 
Table 1. Sustainable SCM criteria and different approaches for assessing sustainability.

\begin{tabular}{|c|c|c|}
\hline Authors & Approaches and techniques & Sustainable SCM criteria \\
\hline Awasthi et al. [29] & $\begin{array}{l}\text { Fuzzy Multi-Criteria Decision } \\
\text { Making (MCDM) }\end{array}$ & Environmental criteria \\
\hline Büyüközkan et al. [30] & $\begin{array}{l}\text { Fuzzy MCDM in the presence of } \\
\text { incomplete information }\end{array}$ & Environmental and economic criteria \\
\hline Erol et al. [31] & Fuzzy MCDM & Environmental criteria \\
\hline Govindan et al. [32] & $\begin{array}{l}\text { Fuzzy MCDM based on triple bottom } \\
\text { line approach }\end{array}$ & Environmental and economic criteria \\
\hline Kuo et al. [33] & Artificial neural network and MADM & Environmental, social, and economic criteria \\
\hline Punniyamoorthy et al. [34] & $\begin{array}{l}\text { Structural equation modeling in } \\
\text { fuzzy context }\end{array}$ & Economic criteria \\
\hline Amindoust et al. [35] & Fuzzy inference system ranking model & Environmental, social, and economic criteria \\
\hline Yeh and Chuang [36] & MCDM by use of Genetic Algorithm & Environmental and economic criteria \\
\hline Azadi et al. [27] & $\begin{array}{l}\text { Enhanced Russell measure DEA model } \\
\text { in fuzzy context }\end{array}$ & Environmental, social, and economic criteria \\
\hline
\end{tabular}

DEA model based on linear programming and Pareto optimal solution. Their main DEA model is based upon BCC (Banker-Charnes-Cooper) model [44].

Amin et al. [45] merged a couple of DMUs and studied whether or not the merged DMU could affect efficiency frontier. Amin et al. [46] used inverse DEA model to recommend higher operational efficiency. Eyni et al. [47] divided inputs/outputs into desirable and undesirable inputs/outputs and applied inverse DEA model to increase desirable outputs and decrease undesirable outputs.

\subsubsection{RAM model}

In real world, there are differences in measurement unit of variables. In addition, in some cases, there might be big ranges in inputs and outputs. Some DEA models can cope with different measurement units, which are called unit invariant models [48]. For instance, CCR [9] and BCC [44] models are considered as unit invariant models. On the other hand, there might be zero and negative values in datasets [49]. Some of DEA models can deal with negative and zero values called translation invariant, i.e., translation of values does not affect results [50]. Additive (ADD) model and BCC model are translation invariant, although the input-oriented
$\mathrm{BCC}$ is invariant under output translation, and vice versa [51]. RAM is an extension of the ADD model, which is both unit and translation invariant [52].

In this paper, a new extension of RAM model is introduced, which is called input/output orientedRAM model (oriented-RAM). Moreover, the inverse oriented-RAM model with network and dynamic structure is proposed.

\subsubsection{Network and dynamic DEA models}

Tone and Tsutsui [53] argued that traditional DEA models dealt with DMUs as black boxes and could not address network structure of DMUs. They proposed a network SBM model and calculated "divisional efficiency" of each division in each DMU. Färe and Grosskopf [54], for the first time, addressed intermediate products and, then, extended their work and developed network DEA model [55]. Sexton and Lewis [56] proposed a two-stage DEA model and extended their work to multi-stage networks. Mirhedayatian et al. [57] proposed a network DEA model to assess green supply chains.

Färe and Grosskopf [12] first introduced dynamic DEA. Tone and Tsutsui [58] proposed a dynamic SBM measure and calculated "term efficiency" for each DMU 
in each period. Chen [59] proposed a network DEA model with dynamic effects on network. Park and Park [60] expanded Debreu-Farrell technical efficiency and applied their multi-period model to cable TV service units. Shabanpour et al. [61] utilized dynamic DEA and artificial neural networks to evaluate past, present, and future efficiencies of green supply chains. Tone and Tsutsui [13] combined network and dynamic DEA models and proposed network dynamic DEA model.

\section{The proposed models}

\subsection{Oriented-RAM model}

Basic RAM model proposed by Cooper et al. [52] is as follows:

$$
\begin{array}{lc}
\max \quad \theta=\frac{1}{m+p}\left(\sum_{i=1}^{m} R_{i}^{x} s_{i}^{x}+\sum_{r=1}^{p} R_{r}^{y} s_{r}^{y}\right), \\
\text { s.t.: } \\
\sum_{j}^{n} x_{i j} \lambda_{j}+s_{i}^{x}=x_{i o}, & i=1, \cdots, m, \\
\sum_{j}^{n} y_{r j} \lambda_{j}-s_{r}^{y}=y_{r o}, & r=1, \cdots, p, \\
\lambda_{j}, s_{i}^{x}, s_{r}^{y} \geq 0, & \forall i, j, r,
\end{array}
$$

where $s_{i}^{x}$ and $s_{r}^{y}$ are distances of $\mathrm{DMU}_{o}$ from efficient frontier. $\quad R_{i}^{x}$ and $R_{r}^{y}$ denote ranges of inputs and outputs calculated as $1 /\left(x_{i}^{U}-x_{i}^{L}\right)$ and $1 /\left(y_{r}^{U}-y_{r}^{L}\right)$, respectively. Upper and lower bounds are specified by $x_{i}^{U}=\max _{j}\left\{x_{i j}\right\}, y_{r}^{U}=\max _{j}\left\{y_{r j}\right\}$ as well as $x_{i}^{L}=$ $\min _{j}\left\{x_{i j}\right\}, y_{r}^{L}=\min _{j}\left\{y_{r j}\right\}$, respectively. Objective function measures inefficiency of $\mathrm{DMU}_{o}$. Efficiency score is calculated by $\theta^{*}=1-(1 / m+p)\left(\sum_{i=1}^{m} R_{i}^{x} s_{i}^{x *}+\right.$ $\sum_{r=1}^{p} R_{r}^{y} s_{r}^{y^{*}}$ ). A DMU (supply chain) is efficient if the objective function of Model (1) is zero, i.e., $s_{i}^{x^{*}}=s_{r}^{y^{*}}=$ 0 . Our new input-oriented RAM model is as follows:

$$
\begin{array}{ll}
\max & \frac{1}{m} \sum_{i=1}^{m} R_{i}^{x} s_{i}^{x}, \\
\text { s.t.: } & \\
\sum_{j}^{n} x_{i j} \lambda_{j}+s_{i}^{x}=x_{i o}, & i=1, \cdots, m, \\
\sum_{j}^{n} y_{r j} \lambda_{j} \geq y_{r o}, & \\
\sum_{j}^{n} \lambda_{j}=1, &
\end{array}
$$

$$
\lambda_{j}, s_{i}^{x} \geq 0, \quad \forall i, j, r
$$

where $R_{i}^{x}$ is $1 /\left(x_{i}^{U}-x_{i}^{L}\right)$.

The reason for proposing the oriented-RAM model is that, in real world, some cases exist in which there might be very a high range of inputs or outputs. On the other hand, in some cases, such as production plants, divisions produce intermediate measures delivered to next divisions. Thus, except for the last division, other divisions cannot deliver outputs to outside of the network (e.g., water refinery). Therefore, ordinary RAM model cannot be utilized. There is a significant difference between our model and the other unit and translation invariant DEA models. Our idea originates from input (output) oriented SBM model proposed by Cooper et al. [51].

Theorem 1. In optimal solution, efficiency score is $0 \leq \theta^{*} \leq 1$

Proof. According to Aida et al. [62], in an optimal solution, there is:

$$
0 \leq-\sum_{j}^{n} x_{i j} \lambda_{j}^{*}+x_{i o}=s_{i}^{x^{*}} \leq x_{i}^{U}-x_{i}^{L} .
$$

Eq. (3) comes from condition $\sum_{j}^{n} \lambda_{j}=1$. Therefore, we have:

$$
0 \leq R_{i}^{x} s_{i}^{x^{*}} \leq 1
$$

Theorem 2. The RAM model is translation invariant. This theorem can be generalized for input-oriented RAM model. Suppose that there are $n$ DMUs with one input and one output. Changes after translation are depicted in Figures 1, 2, and 3.

As is observed, in Figures 1, 2, and 3, translation cannot change direction or amount of efficiency improvement.

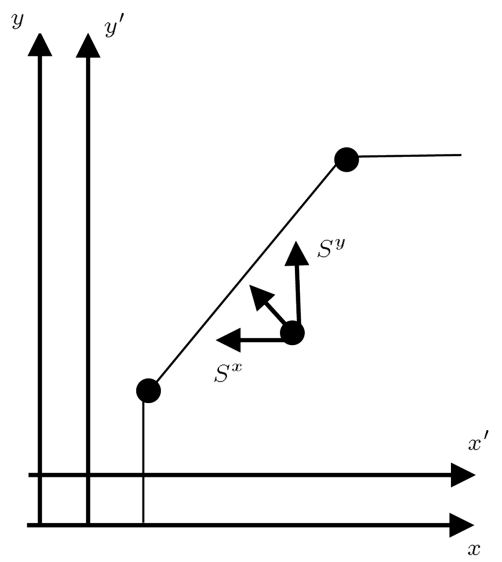

Figure 1. Basic RAM. 


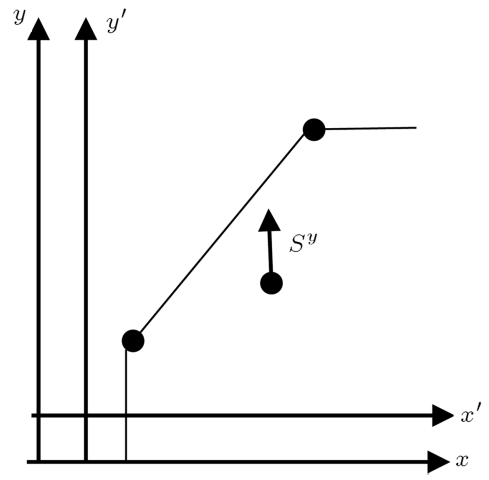

Figure 2. Output oriented-RAM model.

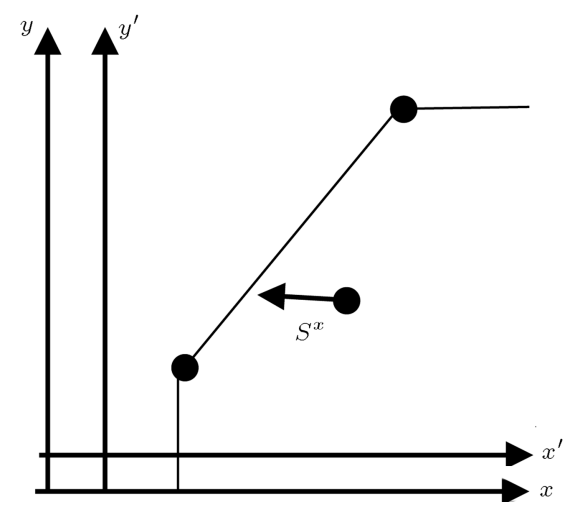

Figure 3. Input oriented-RAM model.

Proof. For proof, see Cooper et al. [63].

Theorem 3. The input-oriented RAM model is unit invariant in inputs. In addition, output-oriented RAM model is unit invariant in outputs, corresponding to the objective function of input (output)-oriented RAM model (Model 2). As is seen, there are only inputs' (outputs') slacks in the objective function.

Now, output-oriented RAM model is proposed. Model (5) has characteristics similar to those of Model (2):

$$
\begin{array}{ll}
\max _{j} \frac{1}{p} \sum_{r=1}^{p} R_{r}^{y} s_{r}^{y}, & \\
\text { s.t.: } & \\
\sum_{j}^{n} x_{i j} \lambda_{j} \leq x_{i o}, & r=1, \cdots, m, \\
\sum_{j}^{n} y_{r j} \lambda_{j}-s_{r}^{y}=y_{r o}, & \\
\sum_{j}^{n} \lambda_{j}=1, & \\
\lambda_{j}, s_{r}^{y} \geq 0, &
\end{array}
$$

Proof. For proof, see Cooper et al. [63].

\subsection{Network-dynamic input-oriented $R A M$ (NDIO-RAM) model}

In this subsection, we extend the input-oriented RAM model to a network dynamic model. Suppose that there are $n$ DMUs $(j=1, \cdots, n)$ with $k$ divisions $(k=$ $1, \cdots, K)$ in each $t$ period $(t=1, \cdots, T)$. Notations are as follows:

$x_{i j k}^{t} \quad$ The $i$ th input of the $j$ th DMU in the

$y_{r j k}^{t} \quad$ The $r$ th output of the $j$ th DMU in the $k$ th division in term $t$;

$l_{w j(k-h)}^{t} \quad$ The $w$ th $(w=1, \cdots, W)$ intermediate measure of the $j$ th DMU sent from the $k$ th division to the $h$ th division in term $t$

$c_{u j k}^{t, t+1} \quad$ The $u$ th $(u=1, \cdots, U)$ carry-over of the $j$ th DMU in the $k$ th division from term $t$ to term $t+1$;

$\lambda_{j k}^{t} \quad$ Intensity vector of the $j$ th DMU in the $k$ th division in term $t$.

At this juncture, the NDIO-RAM model is proposed as follows:

$$
\max \frac{1}{T} \sum_{t=1}^{T} \frac{1}{K} \sum_{k=1}^{K} \frac{1}{m} \sum_{i=1}^{m} R_{i o k}^{x^{t}} s_{i o k}^{x^{t}},
$$

s.t.:

$\sum_{j}^{n} x_{i j k}^{t} \lambda_{j k}^{t}+s_{i o k}^{x^{t}}=x_{i o k}^{t}$,

$i=1, \cdots, m, \quad \forall K, T$,

$\sum_{j}^{n} y_{r j k}^{t} \lambda_{j k}^{t} \geq y_{\text {rok }}^{t}, \quad r=1, \cdots, p, \quad \forall K, T$,

$\sum_{j}^{n} l_{w j(k-h)}^{t} \lambda_{j k}^{t}=\sum_{j}^{n} l_{w j(k-h)}^{t} \lambda_{j h}^{t}$,

$w=1, \cdots, W, \quad \forall K, T$,

$\sum_{j}^{n} c_{u j k}^{t, t+1} \lambda_{j k}^{t}=\sum_{j}^{n} c_{u j k}^{t, t+1} \lambda_{j k}^{t+1}$

$u=1, \cdots, U, \quad t=1, \cdots, T-1, \quad \forall K$,

$\sum_{j}^{n} \lambda_{j k}^{t}=1, \quad \forall K, T$ 


$$
\lambda_{j k}^{t}, s_{i o k}^{x^{t}} \geq 0, \quad \forall i, j, r
$$

Model (6) is a general model in which there is no preference for divisions, inputs, and terms. Intermediate measures and carry-overs have indirect impact on objective function.

\subsection{Inverse oriented-RAM model}

For the first time, Wei et al. [37] introduced the following inverse (Models (7) and (8)). Their inverse model was derived from a general radial output-oriented DEA model.

$$
\begin{aligned}
& \max \quad z_{0}, \\
& \text { s.t.: } \\
& \sum_{j}^{n} x_{i j} \lambda_{j} \leq x_{i o}, \quad i=1, \cdots, m, \\
& \sum_{j}^{n} y_{r j} \lambda_{j} \geq y_{r o} z_{0}, \quad r=1, \cdots, p, \\
& \delta_{1}\left(\sum_{j}^{N} \lambda_{j}+\delta_{2}(-1)^{\delta_{3}} v\right)=\delta_{1}, \\
& \lambda_{j}, v \geq 0, \quad \forall i, j, r .
\end{aligned}
$$

Parameters $\delta_{1}, \delta_{2}$, and $\delta_{3}$ can have only 0 or 1 values:

- If $\delta_{1}=0$, then Model ( 7$)$ is a CCR model;

- If $\delta_{1}=1$ and $\delta_{2}=0$, then Model (7) is a BCC model;

- If $\delta_{1}=\delta_{2}=1$ and $\delta_{3}=0$, then Model (7) is a non-increasing model;

- If $\delta_{1}=\delta_{2}=\delta_{3}=1$, then Model ( 7 ) is a nondecreasing model.

Wei et al. [37] supposed that inputs of $\mathrm{DMU}_{o}\left(x_{i o}\right)$ increased to a given value, i.e., $a_{i}$. Then, they tried to determine proper values for $\beta_{r}$ given that objective function values of Models (7) and (8) are equal, i.e., $z_{o}^{*}=z_{i n v}^{*}$. Wei et al. [37] proposed a new dummy $\mathrm{DMU}_{n+1}$ with input vector $a_{i o}$ and output vector $\beta_{\text {ro }}$, where $a_{i o}=x_{i o}+\Delta x_{i o}$ and $\beta_{\text {ro }}=y_{\text {ro }}+\Delta y_{\text {ro }}$.

$$
\begin{aligned}
& \max z_{i n v}, \\
& \text { s.t.: } \\
& \sum_{j}^{n} x_{i j} \lambda_{j}+\alpha_{i 0} \lambda_{n+1} \leq \alpha_{i 0}, \quad i=1, \cdots, m, \\
& \sum_{j}^{n} y_{r j} \lambda_{j}+\beta_{r o} \lambda_{n+1} \geq \beta_{\text {ro }} z_{i n v},
\end{aligned}
$$

$$
\begin{aligned}
& \delta_{1}\left(\sum_{j}^{N} \lambda_{j}+\lambda_{n+1}+\delta_{2}(-1)^{\delta_{3}} v\right)=\delta_{1}, \\
& \lambda_{j}, v \geq 0, \quad \forall i, j=1,2, \cdots, n+1, r .
\end{aligned}
$$

In our proposed model, there are not any given predetermined values for neither $a_{i o}$ nor $\beta_{\text {ro }}$. Model (13) is a multi-objective linear programme that determines $a_{i o}$ and $\beta_{\text {ro }}$.

Definition 1. Let the optimal solution for the following input-oriented RAM model be $\left(z_{0}^{*}, \lambda_{j}^{*}, s_{i}^{x^{*}}\right)$ :

$$
\begin{array}{ll}
\max \quad z_{0}=\frac{1}{m} \sum_{i=1}^{m} R_{i}^{x} s_{i}^{x}, & \\
\text { s.t.: } & \\
\sum_{j}^{n} x_{i j} \lambda_{j}+s_{i}^{x}=x_{i o}, & r=1, \cdots, m, \\
\sum_{j}^{n} y_{r j} \lambda_{j} \geq y_{r o}, & \\
\sum_{j}^{n} \lambda_{j}=1, & \\
\lambda_{j}, s_{i}^{x} \geq 0, & \forall i, j, r .
\end{array}
$$

Definition 2. The input-oriented RAM inverse model can be formulated as Model (10), and its optimal solution is $\left(z_{i n v}^{*}, \lambda_{j}^{*}, \lambda_{j+1}^{*}, s_{i}^{\bar{a}^{*}}\right)$ :

$$
\max \quad z_{i n v}=\frac{1}{m} \sum_{i=1}^{m} R_{i}^{x} s_{i}^{\bar{\alpha}},
$$

s.t.:

$$
\begin{aligned}
& \sum_{j}^{n} x_{i j} \lambda_{j}+\bar{\alpha}_{i o} \lambda_{n+1}+s_{i}^{\bar{\alpha}}=\bar{\alpha}_{i o}, \\
& i=1, \cdots, m, \\
& \sum_{j}^{n} y_{r j} \lambda_{j}+\left(y_{r o}+\Delta \bar{y}_{r o}\right) \lambda_{n+1} \geq y_{r o}+\Delta \bar{y}_{r o}, \\
& r=1, \cdots, p, \\
& \sum_{j}^{n} \lambda_{j}+\lambda_{n+1}=1, \\
& \lambda_{j}, \lambda_{n+1}, s_{i}^{\bar{\alpha}} \geq 0, \quad \forall i, j, r .
\end{aligned}
$$

Given the assumption, $z_{0}^{*}$ from Model (9) and $z_{i n v}^{*}$ from Model (10) have similar values. In addition, 
$R_{i}^{x}$ is assumed constant as we want to keep efficiency frontier unchanged. Therefore, the following equation is considered:

$$
\frac{1}{m} \sum_{i=1}^{m} R_{i}^{x} s_{i}^{x^{*}}=\frac{1}{m} \sum_{i=1}^{m} R_{i}^{x} s_{i}^{\bar{\alpha}^{*}} .
$$

As a result:

$$
s_{i}^{x^{*}}=s_{i}^{\bar{\alpha}^{*}} .
$$

Now, a multi-objective linear programme (13) is utilized that determines $\alpha_{i o}$ and $\Delta y_{\text {ro }}$, simultaneously, where $\alpha_{i o}=x_{i o}+\Delta x_{i o}$ :

$$
\begin{aligned}
& \min \quad \alpha_{i o}, \\
& \text { s.t.: } \\
& \sum_{j}^{n} x_{i j} \lambda_{j}+s_{i}^{x^{*}}=\alpha_{i o}, \quad i=1, \cdots, m, \\
& \sum_{j}^{n} y_{r j} \lambda_{j}=y_{r o}+\Delta y_{r o}, \\
& \alpha_{i o} \geq x_{i o}, \\
& \lambda_{j} \geq 0, \\
& \Delta y_{r o}: \text { free. }
\end{aligned}
$$

In the first constraint of Model (13), $s_{i}^{\alpha}$ is replaced by $s_{i}^{x^{*}} . \quad R_{i}^{x}$ is assumed to be constant. The last condition of Model (13) guarantees that purpose.

Definition 3. Suppose that $\bar{\alpha}_{i o}, \Delta \bar{y}_{r o}$, and $\bar{\lambda}_{j}$ are feasible solutions. If there is no feasible solution such as $\alpha_{i}<\bar{\alpha}_{i o},\left(\bar{\alpha}_{i o}, \Delta \bar{y}_{r o}, \bar{\lambda}_{j}\right)$ can be a weak Pareto solution for Model (13).

Theorem 4. $\left(\bar{\alpha}_{i o}, \Delta \bar{y}_{r o}, \bar{\lambda}_{j}\right)$ is a weak Pareto solution for Model (13) and $z_{o}^{*}$ is the optimal objective function value for Model (9). $\quad z_{R A}^{*}$ is the optimal objective function value for Model (14):

$$
\begin{aligned}
& \max \quad z_{R A}=\frac{1}{m} \sum_{i=1}^{m} R_{i}^{x} s_{i}^{\alpha}, \\
& \text { s.t.: } \\
& \sum_{j}^{n} x_{i j} \lambda_{j}+s_{i}^{\alpha}=\bar{\alpha}_{i o}, \quad i=1, \cdots, m, \\
& \sum_{j}^{n} y_{r j} \lambda_{j} \geq y_{r o}+\Delta \bar{y}_{r o}, \quad r=1, \cdots, p, \\
& \sum_{j}^{n} \lambda_{j}=1,
\end{aligned}
$$

$$
\lambda_{j}, s_{i}^{\alpha} \geq 0, \quad \forall i, j, r .
$$

Proof. Model (14) has an optimal solution $\left(z_{R A}^{*}, \lambda_{j}^{\alpha}\right.$, $\left.s_{i}^{\alpha^{*}}\right)$. The optimal solution of Model (13) is embedded in its first constraint and that of Model (14) in its first constraints. Therefore, given Model (13), we have:

$$
\sum_{j}^{n} x_{i j} \bar{\lambda}_{j}+s_{i}^{x^{*}}=\bar{\alpha}_{i o} .
$$

In addition, given Model (14), we have:

$$
\sum_{j}^{n} x_{i j} \lambda_{j}^{\alpha}+s_{i}^{\alpha^{*}}=\bar{\alpha}_{i o} .
$$

Consequently:

$$
\sum_{j}^{n} x_{i j} \lambda_{j}^{\alpha}+s_{i}^{\alpha^{*}}=\sum_{j}^{n} x_{i j} \bar{\lambda}_{j}+s_{i}^{x^{*}} .
$$

Furthermore, given Definition 3 and Model (14), we know the optimal solution of Model (13), and $\left(\bar{\alpha}_{i o}\right.$, $\left.\Delta \bar{y}_{\text {ro }}, \bar{\lambda}_{j}\right)$ is a feasible solution for Model (14). Given Models (9) and (14) and Definition 3, we have:

$$
z_{R A}^{*} \geq z_{o}^{*} .
$$

As mentioned earlier, $R_{i}^{x}$ remains constant. Therefore:

$$
s_{i}^{\alpha^{*}} \geq s_{i}^{x^{*}} .
$$

If $z_{R A}^{*}>z_{o}^{*}$, then:

$$
s_{i}^{\alpha^{*}}>s_{i}^{x^{*}} \text {. }
$$

By Eqs. (17) and (20), we have:

$$
\sum_{j}^{n} x_{i j} \lambda_{j}^{\alpha}<\sum_{j}^{n} x_{i j} \bar{\lambda}_{j}
$$

To convert Expression (21) to an equation, $h>0$ is added to left-hand side of Expression (21).

$$
\sum_{j}^{n} x_{i j} \lambda_{j}^{\alpha}+h=\sum_{j}^{n} x_{i j} \bar{\lambda}_{j} .
$$

Now, we substitute $\sum_{j}^{n} x_{i j} \lambda_{j}^{\alpha}+h$ by $\sum_{j}^{n} x_{i j} \bar{\lambda}_{j}$ in the first constrain of Model (13).

$$
\sum_{j}^{n} x_{i j} \lambda_{j}^{\alpha}+s_{i}^{x^{*}}=\alpha_{i o}-h .
$$

Therefore, we have a feasible solution $\left(\lambda_{j}^{\alpha}, \bar{\alpha}_{i o}-\bar{h}\right)$ for Model (13), while we know that Model (13) has a weak Pareto solution $\left(\bar{\alpha}_{i o}, \bar{\lambda}_{j}\right)$. Therefore, we have $z_{R A}^{*}=z_{o}^{*}$. Then, $h=0$. By Theorem 4, the relationship between Models (14) and (13) is examined.

Theorem 5. Models (9) and (14) have similar objective function values: $z_{R A}^{*}=z_{o}^{*}$. 
Proof. Given Theorem 4, we know that $s_{i}^{\alpha^{*}}=s_{i}^{x^{*}}$. Thus, there is $\frac{1}{m} \sum_{i=1}^{m} R_{i}^{x} s_{i}^{\alpha^{*}}=\frac{1}{m} \sum_{i=1}^{m} R_{i}^{x} s_{i}^{x^{*}}$.

Theorem 6. Models (10) and (14) have similar objective function values: $z_{R A}^{*}=z_{i n v}^{*} s$.

Proof. Let $\left(z_{i n v}^{*}, \lambda_{j}^{*}, \lambda_{j+1}^{*}, s_{i}^{\bar{a}^{*}}\right)$ be the optimal solution of Model (10) and $z_{i n v}^{*} \geq 0$. We suppose that $z_{i n v}^{*}>0$. If $z_{i n v}^{*}>0$, then $\lambda_{n+1}=0$. In this case, we add a new constraint $\left(\lambda_{n+1}=0\right)$ to Model (10) so that it becomes similar to Model (14). We can prove it by another manner. The dual of Model (10) is as follows:

$$
\begin{aligned}
& \min \sum_{i}^{m} v_{i} \bar{\alpha}_{i O}-\sum_{r}^{p} u_{r}\left(\bar{y}+\Delta \bar{y}_{r o}\right)+\theta, \\
& \text { s.t.: } \\
& \sum_{i}^{m} v_{i} x_{i O}-\sum_{r}^{p} u_{r} y_{r j}+\theta \geq 0, \quad \forall j, \\
& \sum_{i}^{m} v_{i} \bar{\alpha}_{i O}-\sum_{r}^{p} u_{r}\left(\bar{y}+\Delta \bar{y}_{r o}\right)+\theta \geq 0, \\
& v_{i} \geq \frac{1}{m R_{i}^{x}}, \quad \forall i, \\
& v_{i}, \theta: \text { free, } \quad u_{r} \geq 0, \quad j=1,2, \cdots, n .
\end{aligned}
$$

Given the relationship between primal and dual problems [64], objective function value of Model (24) is similar to that of Model (10). Therefore, the second constraint of Model (24) should be an inequality. Thus, this constraint is redundant. Consequently, Model (24) is similar to Model (25). The only difference between Model (24) and Model (25) is the second constraint of Model (24).

$$
\begin{aligned}
& \min \sum_{i}^{m} v_{i} \bar{\alpha}_{i O}-\sum_{r}^{p} u_{r}\left(\bar{y}+\Delta \bar{y}_{r o}\right)+\theta, \\
& \text { s.t.: } \\
& \begin{array}{l}
\sum_{i}^{m} v_{i} x_{i O}-\sum_{r}^{p} u_{r} y_{r j}+\theta \geq 0, \quad \forall j, \\
v_{i} \geq \frac{1}{m R_{i}^{x}}, \quad \forall i, \\
v_{i}, \theta: \text { free, } \quad u_{r} \geq 0, \quad j=1,2, \cdots, n .
\end{array}
\end{aligned}
$$

Note that Model (25) is the dual of Model (10). In Model (10), the first set of constraints has equity sign. Therefore, the related dual variable $\left(v_{i}\right)$ is free in sign.

Theorem 7. Let $\left(z_{o}^{*}, \lambda_{j}^{*}\right.$, and $\left.s_{i}^{x^{*}}\right)$ be the optimal solution of Model (9) and $\left(z_{i n v}^{*}, \lambda_{j}^{*}, \lambda_{j+1}^{*}\right.$, and $\left.s_{i}^{\bar{a}^{*}}\right)$ be the optimal solution of Model (10). Then, $z_{i n v}^{*}=z_{o}^{*}$.

Proof. Given Theorems 4 and 5, it is proved that Models (9) and (14) have similar objective function values. Furthermore, in Theorem 6, we proved that Models (14) and (10) have similar objective function values. As a result, given Theorems 4, 5, and 6, Models (9) and (10) have similar objective function values.

\subsection{Numeric example}

Suppose that there are 8 DMUs, and each DMU has 2 inputs $(x 1$ and $x 2$ ) and 2 outputs ( $y 1$ and $y 2)$. Data are shown in Table 2.

Given input-oriented RAM model (Model 9), Table 3 demonstrates efficiency scores of DMUs and distances of $\mathrm{DMU}_{o}$ from efficient frontier, where $s_{1}^{x^{*}}$ and $s_{2}^{x^{*}}$ are distances of $\mathrm{DMU}_{o}$ from efficient frontier for input 1 and input 2, respectively.

Now, Model (13) is utilized and $s_{1}^{x^{*}}$ and $s_{2}^{x^{*}}$ are considered to determine $\alpha_{i o}$ and $\Delta y_{\text {ro }}$, where $\alpha_{i o}=$ $x_{i o}+\Delta x_{i o}$. Results are shown in Table 4. Given Model (14) and Table 4, efficiency scores of inverse models are shown in Table 5.

As is seen, the efficiency scores in Tables 3 and 5 are similar, although some outputs have changed, yet inputs remain unchanged.

\subsection{The inverse network-dynamic input-oriented RAM model}

In a classical approach, a decision-maker changes outputs (inputs) and solves Model (8) for calculating a new set of inputs (outputs). Herein, for the first time, two approaches are proposed:

Approach 1. Given the presented theorems, here, we extend the inverse input-oriented RAM Model (10) to inverse network-dynamic input-oriented RAM model, proposed as follows:

$$
\max \frac{1}{T} \sum_{t=1}^{T} \frac{1}{K} \sum_{k=1}^{K} \frac{1}{m} \sum_{i=1}^{m} R_{i o k}^{x^{t}} s_{i o k}^{x^{t}},
$$

Table 2. Numeric example dataset.

\begin{tabular}{cccccc}
\hline \multirow{2}{*}{ DMUs } & \multicolumn{2}{c}{ Inputs } & & \multicolumn{2}{c}{ Outputs } \\
\cline { 2 - 3 } \cline { 5 - 6 } & $\boldsymbol{x}_{\boldsymbol{1}}$ & $\boldsymbol{x}_{\boldsymbol{2}}$ & & $\boldsymbol{y}_{\mathbf{1}}$ & $\boldsymbol{y}_{\mathbf{2}}$ \\
\hline $\mathrm{A}$ & 3 & 5 & & 13 & 13 \\
$\mathrm{~B}$ & 2 & 4 & & 12 & 13 \\
$\mathrm{C}$ & 5 & 7 & & 15 & 15 \\
$\mathrm{D}$ & 4 & 6 & & 14 & 15 \\
$\mathrm{E}$ & 8 & 10 & & 18 & 13 \\
$\mathrm{~F}$ & 9 & 13 & & 19 & 17 \\
$\mathrm{G}$ & 1 & 2 & & 20 & 15 \\
$\mathrm{H}$ & 14 & 10 & & 11 & 10 \\
\hline
\end{tabular}


Table 3. Efficiency scores of DMUs.

\begin{tabular}{ccccccccc}
\hline DMUs & A & B & C & D & E & F & G & H \\
\hline Efficiency scores & 0.7867 & 0.8706 & 0.6189 & 0.7028 & 0.3672 & 1 & 1 & 0.1363 \\
\hline$S_{1}^{x^{*}}$ & 2 & 1 & 4 & 3 & 7 & 0 & 0 & 13 \\
$S_{2}^{x^{*}}$ & 3 & 2 & 5 & 4 & 8 & 0 & 0 & 8 \\
\hline
\end{tabular}

Table 4. Results of Model (13).

\begin{tabular}{|c|c|c|c|c|}
\hline \multirow{2}{*}{ DMUs } & \multicolumn{2}{|c|}{$\begin{array}{l}\text { Changes } \\
\text { in inputs }\end{array}$} & \multicolumn{2}{|c|}{$\begin{array}{c}\text { Changes } \\
\text { in outputs }\end{array}$} \\
\hline & $\Delta x_{10}$ & $\Delta x_{20}$ & $\Delta y_{10}$ & $\Delta y_{20}$ \\
\hline A & 0 & 0 & 7 & 2 \\
\hline B & 0 & 0 & 8 & 2 \\
\hline $\mathrm{C}$ & 0 & 0 & 5 & 0 \\
\hline $\mathrm{D}$ & 0 & 0 & 6 & 0 \\
\hline $\mathrm{E}$ & 0 & 0 & 2 & 2 \\
\hline $\mathrm{F}$ & 0 & 0 & 0 & 0 \\
\hline G & 0 & 0 & 0 & 0 \\
\hline $\mathrm{H}$ & 0 & 0 & 9 & 5 \\
\hline
\end{tabular}

s.t.:

$\sum_{j}^{n} x_{i j k}^{t} \lambda_{j k}^{t}+s_{i o k}^{x^{t}}=x_{i o k}^{t}, \quad i=1, \cdots, m$,

$$
\forall K, T
$$$$
\sum_{j}^{n} y_{r j k}^{t} \lambda_{j k}^{t} \geq y_{\text {rok }}^{t}, \quad r=1, \cdots, p,
$$

$\forall K, T$

$\sum_{j}^{n} l_{w j(k-h)}^{t} \lambda_{j k}^{t}=\sum_{j}^{n} l_{w j(k-h)}^{t} \lambda_{j h}^{t}$

$w=1, \cdots, W, \quad \forall K, T$,

$\sum_{j}^{n} c_{u j k}^{t, t+1} \lambda_{j k}^{t} \geq c_{u o k}^{t, t+1}$

$u=1, \cdots, U, \quad t=1, \cdots, T-1, \quad \forall K$,

$\sum_{j}^{n} c_{u j k}^{t, t+1} \lambda_{j k}^{t}=\sum_{j}^{n} c_{u j k}^{t, t+1} \lambda_{j k}^{t+1}$

$u=1, \cdots, U, \quad t=1, \cdots, T-1, \quad \forall K$,

$$
\begin{array}{ll}
\sum_{j}^{n} \lambda_{j k}^{t}=1, & \forall K, T, \\
\lambda_{j k}^{t}, s_{i o k}^{x^{t}} \geq 0, & \forall i, j, r .
\end{array}
$$

Tone and Tsutsui [13] classified intermediate measures into four categories: free, fixed (nondiscretionary), input intermediate, and output intermediates. In addition, they classified carry-overs into four categories: good, bad, free, and fixed carryovers. Model (26) demonstrates a case with fixed intermediate measures and good carry-overs. The third set of constraints of Model (26) connects two divisions. Moreover, the fifth set of constraints of Model (26) links two consecutive terms. Given Tone and Tsutsui [13] classification, good carry-overs play a role of outputs. As a result, in Model (26), we have good carry-overs addressed in the fourth set of constraints.

Model (27) is a multi-objective linear programme. It determines $\alpha_{i o k}^{t}, \Delta y_{r o k}^{t}$, and $\Delta c_{\text {uok }}^{t, t+1}$, where $\left(\alpha_{i o k}^{t}=\right.$ $\left.x_{i o k}^{t}+\Delta x_{i o k}^{t}\right)$. The optimal solution of Model (27) is $\left(\alpha_{i o k}^{t^{*}}, \Delta y_{\text {rok }}^{t^{*}}, \Delta c_{u o k}^{t, t+1^{*}}\right.$, and,$\left.\lambda_{j k}^{t^{*}}\right)$.

$\min \alpha_{i o k}^{t}$,

s.t.:

$\sum_{j}^{n} x_{i j k}^{t} \lambda_{j k}^{t}+s_{i o k}^{x^{t^{*}}}=\alpha_{i o k}^{t}, \quad i=1, \cdots, m$

$\forall K, T$,

$\sum_{j}^{n} y_{r j k}^{t} \lambda_{j k}^{t}=y_{r o k}^{t}+\Delta y_{r o k}^{t}, \quad r=1, \cdots, p$,

$\forall K, T$,

$\sum_{j}^{n} l_{w j(k-h)}^{t} \lambda_{j k}^{t}=\sum_{j}^{n} l_{w j(k-h)}^{t} \lambda_{j h}^{t}$,

$w=1, \cdots, W, \quad \forall K, T$,

Table 5. Efficiency scores of inverse models.

\begin{tabular}{ccccccccc}
\hline DMUs & A & B & C & D & E & F & G & H \\
\hline Efficiency scores & 0.7867 & 0.8706 & 0.6189 & 0.7028 & 0.3672 & 1 & 1 & 0.1363 \\
\hline
\end{tabular}




$$
\begin{aligned}
& \sum_{j}^{n} c_{u j k}^{t, t+1} \lambda_{j k}^{t}=c_{u o k}^{t, t+1}+\Delta c_{u o k}^{t, t+1}, \\
& u=1, \cdots, U, \quad t=1, \cdots, T-1, \quad \forall K, \\
& \sum_{j}^{n} c_{u j k}^{t, t+1} \lambda_{j k}^{t}=\sum_{j}^{n} c_{u j k}^{t, t+1} \lambda_{j k}^{t+1}, \\
& u=1, \cdots, U, \quad t=1, \cdots, T-1, \quad \forall K, \quad \forall K, T, \\
& \alpha_{i o k}^{t} \geq x_{i o k}^{t}, \quad i=1, \cdots, m, \quad \forall K, \quad \forall K, T, \\
& \sum_{j}^{n} \lambda_{j k}^{t}=1, \quad \forall i, j, r, t . \\
& \lambda_{j k}^{t} \geq 0, \quad \Delta y_{\text {rok }}^{t}, \Delta c_{u o k}^{t, t+1}: \text { free, }
\end{aligned}
$$

Model (27) minimizes inputs and determines changes of normal outputs, intermediate outputs, and good carry-overs. Expression $\alpha_{i o k}^{t} \geq x_{i o k}^{t}$ does not let the inputs be decreased to less than original inputs. Thus, Models (26) and (28) have similar input ranges $\left(R_{i o k}^{x^{t}}=R_{i o k}^{\alpha^{t^{*}}}\right)$. Finally, inverse network-dynamic input-oriented RAM model is as follows:

$$
\max \frac{1}{T} \sum_{t=1}^{T} \frac{1}{K} \sum_{k=1}^{K} \frac{1}{m} \sum_{i=1}^{m} R_{i o k}^{\alpha^{t^{*}}} s_{i o k}^{\alpha^{t}}
$$

s.t.:

$$
\begin{aligned}
& \sum_{j}^{n} x_{i j k}^{t} \lambda_{j k}^{t}+\alpha_{i o k}^{t^{*}} \lambda_{(n+1) k}^{t}+s_{i o k}^{\alpha^{t}}=\alpha_{i o k}^{t^{*}}, \\
& i=1, \cdots, m, \quad \forall K, T, \\
& \sum_{j}^{n} y_{r j k}^{t} \lambda_{j k}^{t}+\left(y_{r o k}^{t}+\Delta \bar{y}_{r o k}^{t}\right) \lambda_{(n+1) k}^{t} \geq y_{\text {rok }}^{t}+\Delta y_{r o k}^{t^{*}}, \\
& r=1, \cdots, p, \quad \forall K, T,
\end{aligned}
$$$$
\sum_{j}^{n} l_{w j(k-h)}^{t} \lambda_{j k}^{t}+l_{w j(k-h)}^{t} \lambda_{(n+1) k}^{t}=\sum_{j}^{n} l_{w j(k-h)}^{t} \lambda_{j h}^{t}
$$$$
+l_{w j(k-h)}^{t} \lambda_{(n+1) h}^{t}
$$$$
w=1, \cdots, W, \quad \forall K, T,
$$$$
\sum_{j}^{n} c_{u j k}^{t, t+1} \lambda_{j k}^{t}+\left(c_{u o k}^{t, t+1}+\Delta c_{u o k}^{t, t+1^{*}}\right) \lambda_{(n+1) k}^{t}
$$$$
\geq c_{u o k}^{t, t+1}+\Delta c_{u o k}^{t, t+1^{*}}
$$$$
u=1, \cdots, U, \quad t=1, \cdots, T-1, \quad \forall K,
$$

$$
\begin{aligned}
& \sum_{j}^{n} c_{u j k}^{t, t+1} \lambda_{j k}^{t}+\left(c_{u o k}^{t, t+1}+\Delta c_{u o k}^{t, t+1^{*}}\right) \lambda_{(n+1) k}^{t} \\
& =\sum_{j}^{n} c_{u j k}^{t, t+1} \lambda_{j k}^{t+1}+\left(c_{u o k}^{t, t+1}+\Delta c_{u o k}^{t, t+1^{*}}\right) \lambda_{(n+1) k}^{t+1}, \\
& u=1, \cdots, U, \quad t=1, \cdots, T-1, \quad \forall K, \\
& \sum_{j}^{n} \lambda_{j k}^{t}+\lambda_{(n+1) k}^{t}=1, \quad \forall K, T, \\
& \lambda_{j k}^{t}, \lambda_{(n+1) k}^{t}, s_{i o k}^{\alpha^{t}} \geq 0, \quad \forall i, j, r .
\end{aligned}
$$

Given the inverse oriented-RAM (Model (10)), only two types of variables, including intermediate measures and carry-overs, are added to Model (28). Intermediate measures and carry-overs do not have direct impact on objective function.

Approach 2. Given Model (27), we propose Model (29). Inputs and outputs are changed simultaneously. In Model (29), despite Model (27), inputs can be reduced to their lower bounds and be increased to their upper bounds. Expression $\underline{x}_{i o k}^{t} \leq x_{i o k}^{t}+\Delta x_{i o k}^{t} \leq \bar{x}_{i o k}^{t}$ guarantees input ranges to remain unchanged. Also $\underline{x}_{i o k}^{t}$ and $\bar{x}_{i o k}^{t}$ are lower and upper bounds of inputs, respectively.

$$
\begin{aligned}
& \min \quad \Delta x_{i o k}^{t}, \\
& \text { s.t.: } \\
& \sum_{j}^{n} x_{i j k}^{t} \lambda_{j k}^{t}+s_{i o k}^{x^{t^{*}}}=x_{i o k}^{t}+\Delta x_{i o k}^{t}, \quad i=1, \cdots, m, \\
& \quad \forall K, T, \\
& \sum_{j}^{n} y_{r j k}^{t} \lambda_{j k}^{t}=y_{r o k}^{t}+\Delta y_{r o k}^{t},
\end{aligned}
$$

$\forall K, T$

$$
\sum_{j}^{n} l_{w j(k-h)}^{t} \lambda_{j k}^{t}=\sum_{j}^{n} l_{w j(k-h)}^{t} \lambda_{j h}^{t}
$$

$$
w=1, \cdots, W, \quad \forall K, T,
$$$$
\sum_{j}^{n} c_{u j k}^{t, t+1} \lambda_{j k}^{t}=c_{u o k}^{t, t+1}+\Delta c_{u o k}^{t, t+1}
$$$$
u=1, \cdots, U, \quad t=1, \cdots, T-1, \quad \forall K,
$$$$
\sum_{j}^{n} c_{u j k}^{t, t+1} \lambda_{j k}^{t}=\sum_{j}^{n} c_{u j k}^{t, t+1} \lambda_{j k}^{t+1}
$$ 


$$
\begin{aligned}
& u=1, \cdots, U, \quad t=1, \cdots, T-1, \quad \forall K, \\
& \underline{x}_{i o k}^{t} \leq x_{i o k}^{t}+\Delta x_{i o k}^{t} \leq \bar{x}_{i o k}^{t}, \\
& i=1, \cdots, m, \quad \forall K, T, \\
& \sum_{j}^{n} \lambda_{j k}^{t}=1, \quad \forall K, T, \\
& \lambda_{j k}^{t} \geq 0, \quad \Delta x_{i o k}^{t}, \Delta y_{\text {rok }}^{t}, \Delta c_{\text {uok }}^{t, t+1}: \text { free, }, \quad \forall i, j, r, t .
\end{aligned}
$$

\section{Case study}

Nirou Moharekeh Industrial Co. (NMI) is an Iranian manufacturer that manufactures spare parts such as different types of gear boxes, splines, and shafts. NMI delivers them to Iran Khodro (an Iranian automaker). NMI has 12 suppliers that provide gear boxes. Dataset is shown in Table 6, which dates back to 2010-2015. Suppliers provide required spare parts of NMI Co. Figure 4 shows the structure of supply chain.

In this paper, we focus on suppliers of NMI Co. Each supplier of NMI has three divisions (see Figure 5). Each division has three inputs (including wage cost, energy cost, and material cost (economic factors)), two good carry-overs (including green programs and ISO

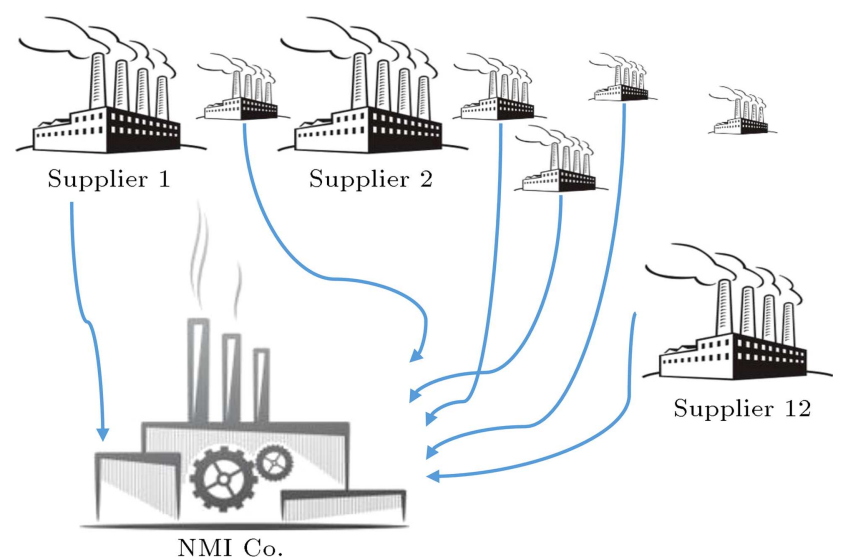

Figure 4. Overall structure of supply chain of NMI.

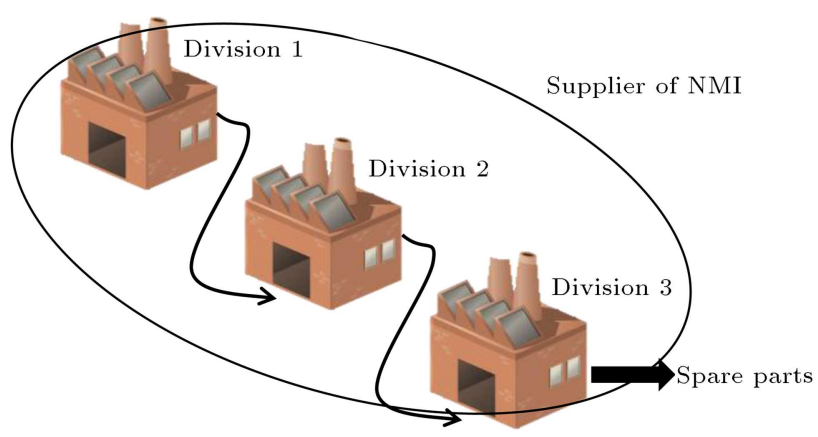

Figure 5. Internal structure of each supplier of NMI.
TS (environmental factor)), and human care programs (social factor). In addition, each division has one fixed intermediate measure (intermediate product) (see Figure 6). First, divisions have only two inputs including wage cost and energy cost.

Figure 6 depicts divisions, inputs, carry-overs, and intermediate measure of the $j$ th supplier of NMI during 6 years. The following notations are defined:

$x_{i j k}^{t} \quad$ The $i$ th input of the $j$ th DMU in the $k$ th division in term $t$;

$l_{w j(k-h)}^{t} \quad$ The $w$ th $(w=1, \cdots, W)$ intermediate measure of the $j$ th DMU which is sent from the $k$ th division to the $h$ th division in term $t$;

$c_{u j k}^{t, t+1} \quad$ The $u$ th $(u=1, \cdots, U)$ carry-over of the $j$ th DMU in the $k$ th division from term $t$ to term $t+1$.

First, DMUs' efficiency scores are calculated in 6 years (terms). Given Table 6, there are huge differences between the smallest and biggest values in inputs (big ranges). Thus, our new (Model (30)) can be used.

$\max \frac{1}{T} \sum_{t=1}^{T} \frac{1}{K} \sum_{k=1}^{K} \frac{1}{m} \sum_{i=1}^{m} R_{i o k}^{x^{t}} s_{i o k}^{x^{t}}$,

s.t.:

$\sum_{j}^{n} x_{i j k}^{t} \lambda_{j k}^{t}+s_{i o k}^{x^{t}}=x_{i o k}^{t}, \quad i=1, \cdots, m$,

$\forall K, T$,

$\sum_{j}^{n} l_{w j(k-h)}^{t} \lambda_{j k}^{t}=\sum_{j}^{n} l_{w j(k-h)}^{t} \lambda_{j h}^{t}$,

$w=1, \cdots, W, \quad \forall K, T$,

$\sum_{j}^{n} c_{u j k}^{t, t+1} \lambda_{j k}^{t} \geq c_{u o k}^{t, t+1}, \quad u=1, \cdots, U$,

$t=1, \cdots, T-1, \quad \forall K$,

$\sum_{j}^{n} c_{u j k}^{t, t+1} \lambda_{j k}^{t}=\sum_{j}^{n} c_{u j k}^{t, t+1} \lambda_{j k}^{t+1}, \quad u=1, \cdots, U$,

$t=1, \cdots, T-1, \quad \forall K$,

$\sum_{j}^{n} \lambda_{j k}^{t}=1, \quad \forall K, T$,

$\lambda_{j k}^{t}, s_{i o k}^{x^{t}} \geq 0, \quad \forall i, j, r$. 


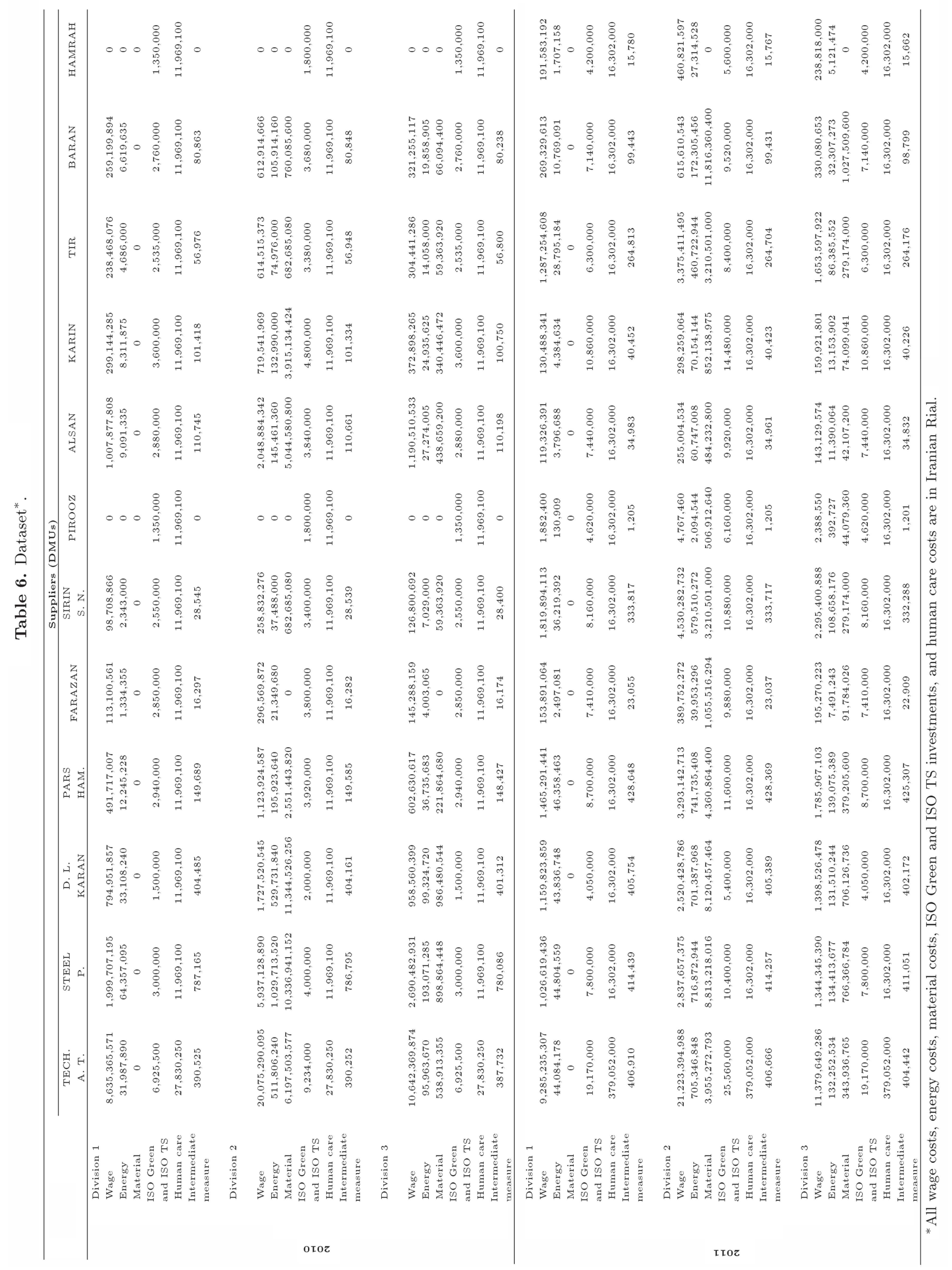




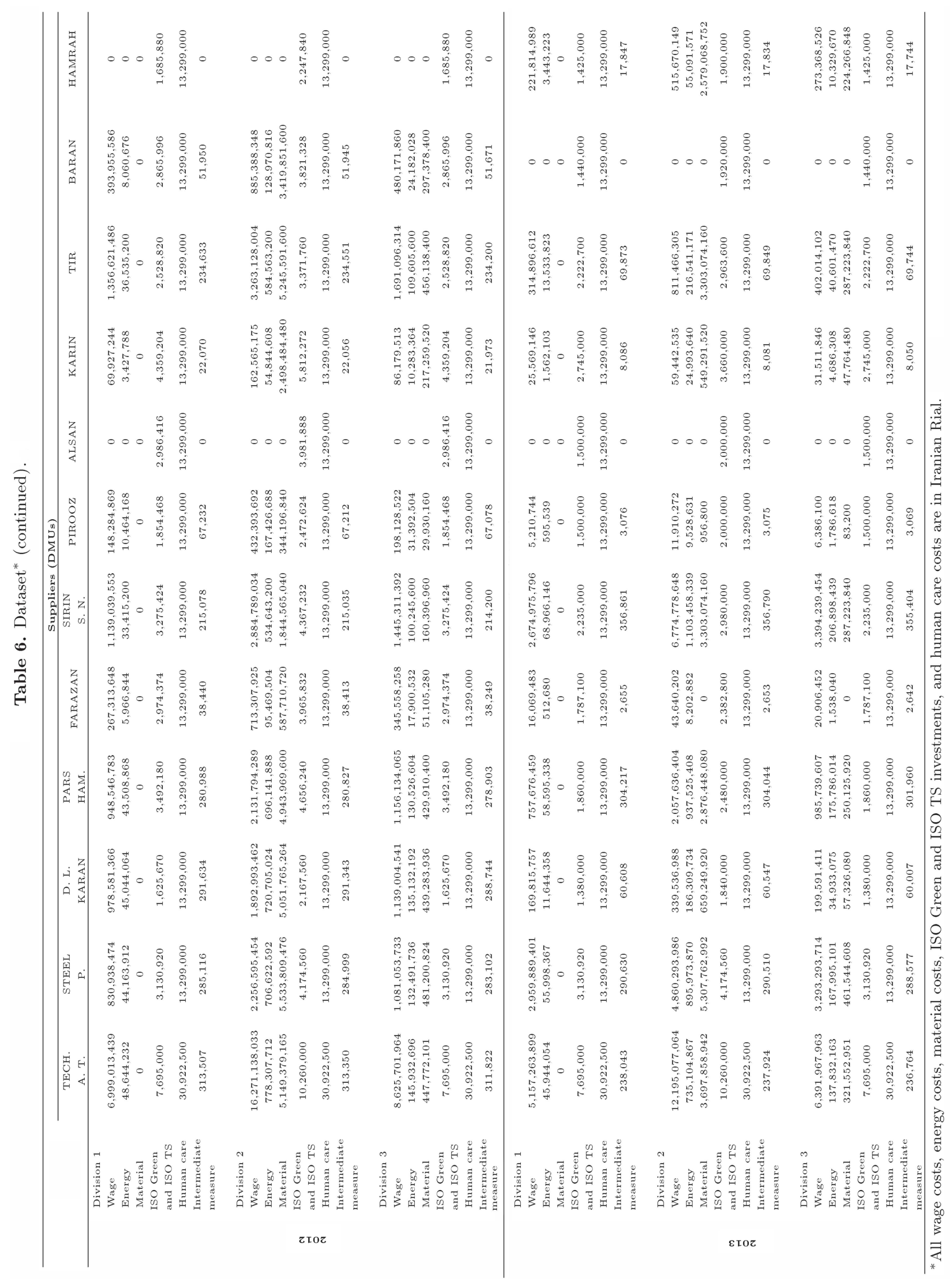




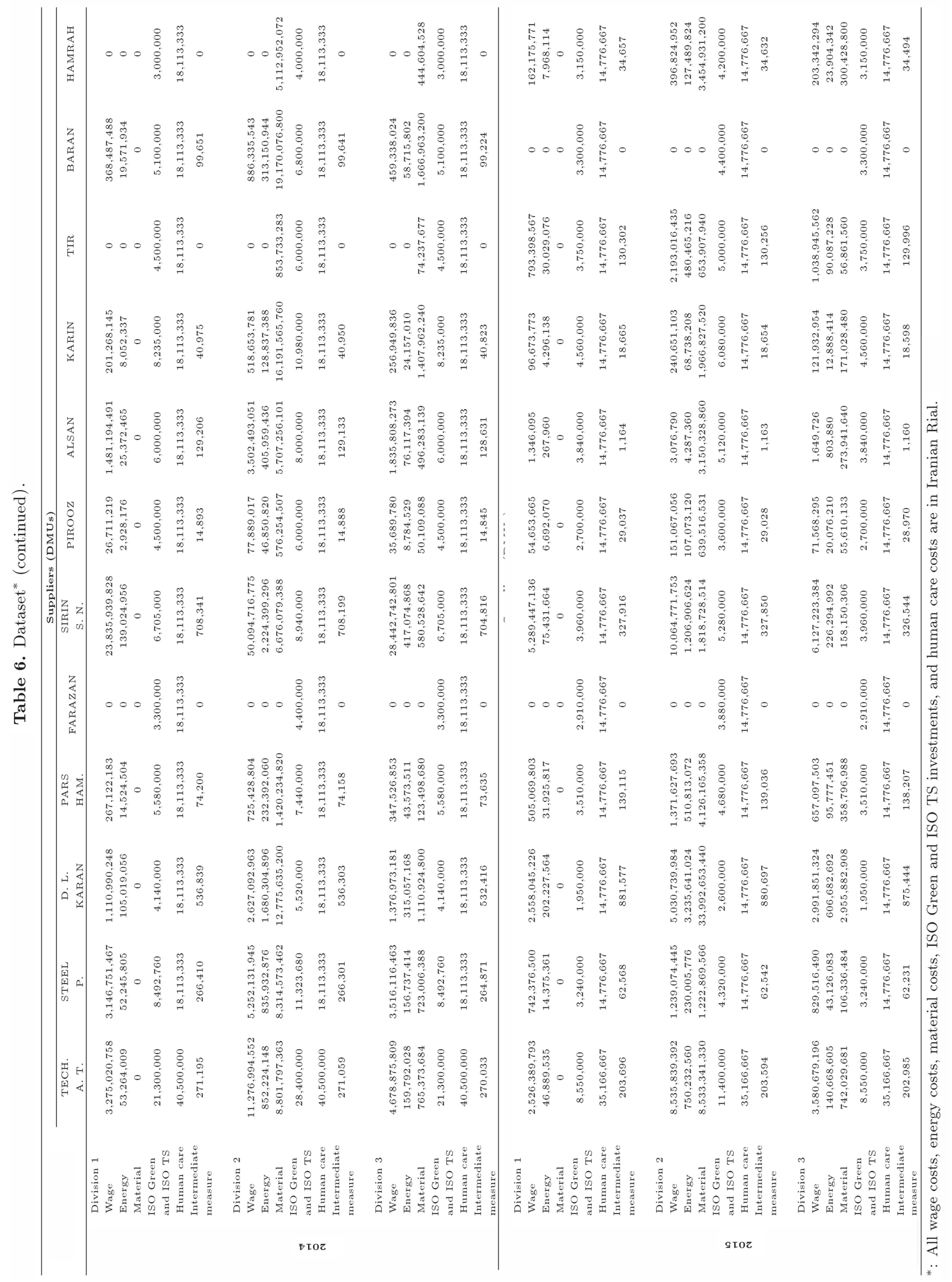




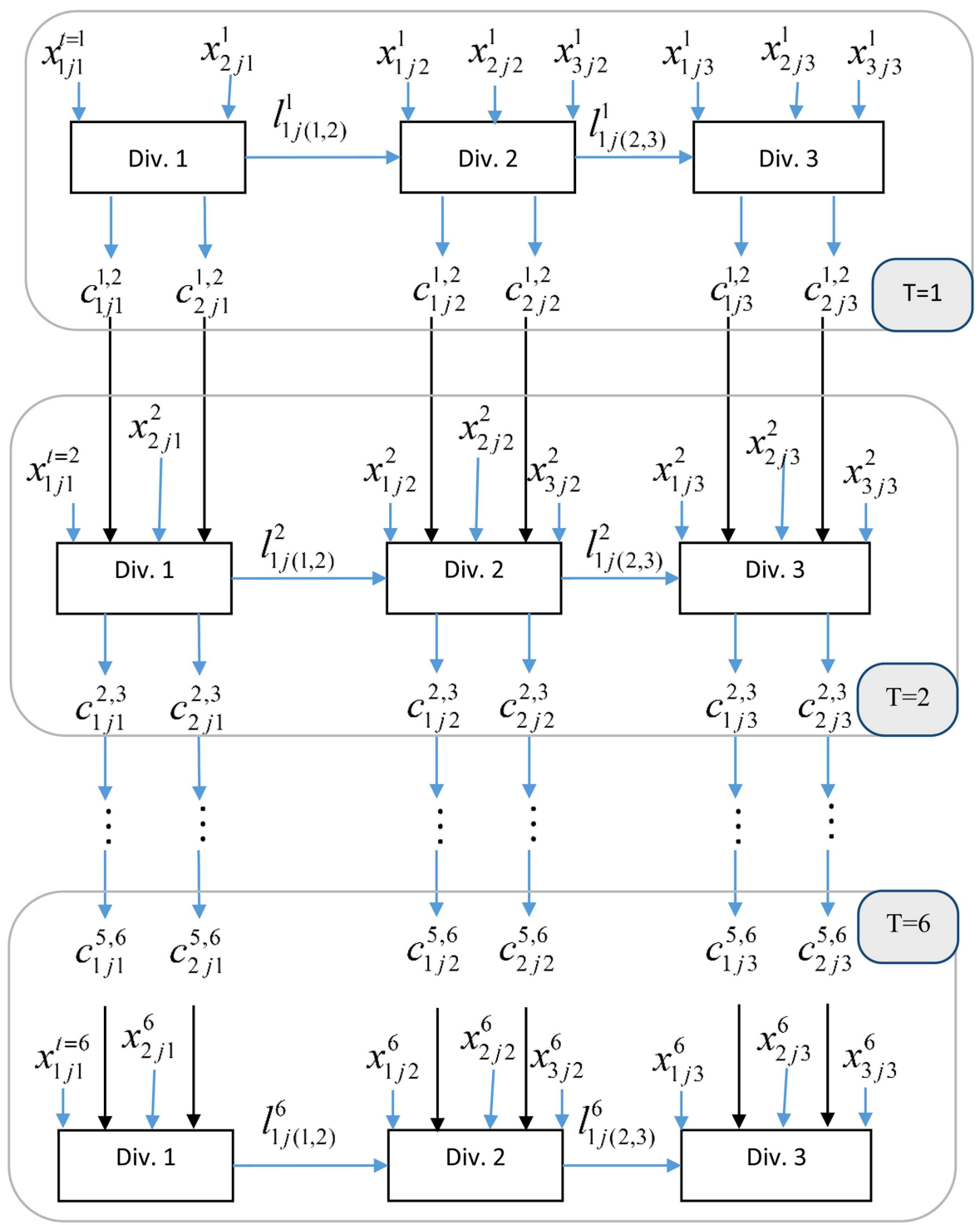

Figure 6. Structure of each supplier of NMI.

Table 7 demonstrates each division's efficiency and efficiency of terms for each supplier of NMI. As is observed in Table 7, DMU D has an increasing trend, while DMU F has a decreasing trend. DMUs A, I, and $\mathrm{L}$ are only overall efficient DMUs.

To determine changes of inputs and outputs, the following model is utilized:

$\min \Delta x_{i o k}^{t}$,

s.t.:

$$
\begin{gathered}
\sum_{j}^{n} x_{i j k}^{t} \lambda_{j k}^{t}+s_{i o k}^{x^{t^{*}}}=x_{i o k}^{t}+\Delta x_{i o k}^{t}, \\
i=1, \cdots, m, \quad \forall K, T,
\end{gathered}
$$

$$
\begin{gathered}
\sum_{j}^{n} l_{w j(k-h)}^{t} \lambda_{j k}^{t}=\sum_{j}^{n} l_{w j(k-h)}^{t} \lambda_{j h}^{t}, \\
w=1, \cdots, W, \quad \forall K, T,
\end{gathered}
$$$$
\sum_{j}^{n} c_{u j k}^{t, t+1} \lambda_{j k}^{t}=c_{u o k}^{t, t+1}+\Delta c_{u o k}^{t, t+1}, \quad u=1, \cdots, U,
$$

$$
t=1, \cdots, T-1, \quad \forall K
$$$$
\sum_{j}^{n} c_{u j k}^{t, t+1} \lambda_{j k}^{t}=\sum_{j}^{n} c_{u j k}^{t, t+1} \lambda_{j k}^{t+1}, \quad u=1, \cdots, U,
$$

$$
t=1, \cdots, T-1, \quad \forall K
$$


Table 7. Efficiency scores.

\begin{tabular}{|c|c|c|c|c|c|c|c|c|c|c|}
\hline \multirow{2}{*}{$\begin{array}{c}\text { DMUs } \\
\text { (suppliers) }\end{array}$} & \multirow{2}{*}{$\begin{array}{l}\text { Overall } \\
\text { efficiency }\end{array}$} & \multicolumn{6}{|c|}{ Term efficiency } & \multicolumn{3}{|c|}{ Divisional efficiency } \\
\hline & & 2010 & 2011 & 2012 & 2013 & 2014 & 2015 & Div. 1 & Div. 2 & Div. 3 \\
\hline TECH. A. T. (A) & 1 & 1 & 1 & 1 & 1 & 1 & 1 & 1 & 1 & 1 \\
\hline STEEL P. (B) & 0.9974 & 1 & 1 & 0.9846 & 1 & 1 & 1 & 1 & 0.9923 & 1 \\
\hline D. L. KARAN (C) & 0.5032 & 0.5441 & 0.4403 & 0.3861 & 0.9004 & 0.5501 & 0.1984 & 0.5672 & 0.4716 & 0.4709 \\
\hline PARS HAM. (D) & 0.7047 & 0.8819 & 0.5157 & 0.4542 & 0.5069 & 0.9941 & 0.8758 & 0.7080 & 0.7022 & 0.7040 \\
\hline FARAZAN (E) & 0.9999 & 1 & 1 & 0.9999 & 1 & 1 & 1 & 0.9999 & 1 & 1 \\
\hline SIRIN S. N. (F) & 0.5396 & 0.9795 & 0.5931 & 0.6245 & 0.2901 & 0.2812 & 0.4691 & 0.4608 & 0.5778 & 0.5802 \\
\hline PIROOZ (G) & 0.9999 & 1 & 1 & 1 & 1 & 1 & 0.9999 & 0.9999 & 1 & 1 \\
\hline $\operatorname{ALSAN}(\mathrm{H})$ & 0.9702 & 0.8215 & 1 & 1 & 1 & 1 & 1 & 0.9817 & 0.9648 & 0.9641 \\
\hline KARIN (I) & 1 & 1 & 1 & 1 & 1 & 1 & 1 & 1 & 1 & 1 \\
\hline $\operatorname{TIR}(\mathrm{J})$ & 0.9206 & 0.9985 & 0.7178 & 0.8746 & 0.9331 & 1 & 1 & 0.9228 & 0.9261 & 0.9130 \\
\hline BARAN (K) & 0.8907 & 0.9459 & 0.7120 & 0.7766 & 1 & 0.9096 & 1 & 0.9555 & 0.8583 & 0.8582 \\
\hline HAMRAH (L) & 1 & 1 & 1 & 1 & 1 & 1 & 1 & 1 & 1 & 1 \\
\hline
\end{tabular}

$$
\begin{array}{cc}
\sum_{j}^{n} \lambda_{j k}^{t}=1, & \forall K, T, \\
\Delta x_{i o k}^{t}, \lambda_{j k}^{t} \geq 0, & \Delta c_{u o k}^{t, t+1}: \text { free, } \quad \forall i, j, r, t .
\end{array}
$$

Results of Model (31) are shown in Table 4. Some points can be derived from the results:

- Inputs experience very low changes $\left(\Delta x_{i j k}^{t}\right)$. Structure of Model (31) addresses this result;

- Manufacturers D. L. KARAN, PARS HAM, SIRIN S. N., and TIR have bigger changes in carry-overs $\left(\Delta c_{u o k}^{t, t+1}\right)$;

- Given DMU TIR, it can be found that DMUs with higher efficiency score may have more changes;

- Carry-overs have large changes. Positive changes of carry-overs imply DMUs' shortfall in investments in green programs, ISO TS programs, and human care programs. Conversely, negative changes imply excess investments.

\section{Managerial implications}

Key factors of sustainability of supply chains are economic, environmental, and social factors. Though the amount of investment in sustainability factors demonstrates management attention to sustainability of supply chains, investment in each sustainability factor should be proportionate. For instance, in Table 8, given results of PARS HAM, we conclude disproportionate investment.

Amount of investment in green programs and ISO TS is more than that of investment in human care programs. Negative carry-over changes indicate excess amounts of investment in green programs and ISO TS. Furthermore, PARS HAM has unbalanced investment in green programs during 6 years. On the other hand, positive changes of carry-over (human care programs) imply shortfall of investment in human care programs. Accordingly, the main finding of the case study is to know whether or not the investment of an organization is proportionate.

\section{Conclusions}

As Seuring and Muller [65] addressed, sustainable supply chain is a growing topic. Carbone et al. [66] argued that a couple of factors triggered companies to apply sustainability principles. Those factors included regulations, scandals, competitors' moves, and customer expectations. Wittstruck and Teuteberg [67] introduced House of Sustainable Supply Chain that had three pillars including environmental performance, economic performance, and social performance. Li [68] claimed that benefits of sustainability, including economic, environmental, and social benefits, should be achieved, simultaneously.

In this paper, a model was proposed to assess sustainability of supply chains. For the first time, we introduced inverse network and dynamic model based upon input-oriented RAM model. As mentioned earlier, RAM model is a unit and translation invariant DEA model. We discussed that the classical inverse DEA models could only determine input or output changes. For the first time, two approaches were proposed to determine input and output changes. The first approach was used to determine which inputs and carryovers, as well as to what extent, should be changed. In the second approach, inputs can be reduced to their 
Table 8. Results of Model (31).

\begin{tabular}{|c|c|c|c|c|c|c|c|c|c|c|c|c|c|c|}
\hline & \multirow{2}{*}{\multicolumn{2}{|c|}{$\begin{array}{c}\Delta X^{*} \\
\text { and } \\
\Delta C^{*}\end{array}$}} & \multicolumn{12}{|c|}{ Suppliers (DMUs) } \\
\hline & & & $\begin{array}{l}\text { TECH. } \\
\text { А. T. }\end{array}$ & $\begin{array}{c}\text { STEEL } \\
\text { P. }\end{array}$ & $\begin{array}{c}\text { D. L. } \\
\text { KARAN }\end{array}$ & $\begin{array}{l}\text { PARS } \\
\text { HAM. }\end{array}$ & FARAZAN & $\begin{array}{l}\text { SIRIN } \\
\text { S. N. }\end{array}$ & PIROOZ & ALSAN & KARIN & TIR & BARAN & HAMRAH \\
\hline \multirow{14}{*}{$\underset{\sim}{0}$} & \multirow{4}{*}{ Div. 1} & $\mathrm{DW}^{1}$ & 0.0 & 0.0 & 0.0 & 0.0 & 0.0 & 0.0 & 0.0 & 0.0 & 0.0 & 0.0 & 0.0 & 0.0 \\
\hline & & $\mathrm{DEN}^{1}$ & $-0.745 \mathrm{E}-8$ & 0.0 & 0.0 & 0.0 & 0.0 & 1.970156 & 0.0 & 0.0084704 & 0.0 & 0.0 & 1.160656 & 0.0 \\
\hline & & DCARGR-TS ${ }^{2}$ & $-0.186 \mathrm{E}-8$ & 0.0 & -4407.17 & -1004242 & $-0.433 \mathrm{E}-7$ & 105469.2 & 0.0 & -0.181928 & $-0.222 \mathrm{E}-6$ & 187368.8 & -103.3697 & 0.0 \\
\hline & & $\mathrm{DCARHC}^{3}$ & $-0.745 \mathrm{E}-8$ & 0.0 & $-0.475 \mathrm{E}-8$ & $-0.104 \mathrm{E}-8$ & 0.305874 & 99.02449 & 0.0 & 0.0 & $0.526 \mathrm{E}-7$ & $0.186 \mathrm{E}-8$ & 0.0 & 0.0 \\
\hline & \multirow{5}{*}{ Div. 2} & DW & 0.0 & 0.0 & 0.0 & 0.0 & 0.0 & 0.0 & 0.0 & 0.0 & 0.0 & 0.0 & 0.0 & 0.0 \\
\hline & & DEN & $-0.103 \mathrm{E}-7$ & 0.0 & 0.0 & 0.0 & 0.0 & 0.0 & 0.0 & 36.1752 & 0.0 & 0.0 & 19.72798 & 0.0 \\
\hline & & $2 \mathrm{DM}^{4}$ & 0.0 & 0.0 & 3781.88 & 0.0 & 0.0 & 26.13003 & 0.0 & 0.0 & 0.0 & 0.0 & 264.9410 & 0.0 \\
\hline & & DCARGR-TS & $0.332 \mathrm{E}-8$ & 0.0 & -3.0411 & -88519.5 & 0.0 & 145506.2 & 0.0 & -0.116260 & $0.521 \mathrm{E}-7$ & -2.026985 & -0.873759 & 0.0 \\
\hline & & DCARHC & $-0.213 \mathrm{E}-8$ & 0.0 & 0.37488 & 167730.6 & 0.0 & 0.0 & 0.0 & -0.364701 & $-0.141 \mathrm{E}-8$ & -0.555666 & 0.0091881 & 0.0 \\
\hline & \multirow{5}{*}{ Div. 3} & DW & 0.0 & 0.0 & 0.0 & 0.0 & 0.0 & 0.0 & 0.0 & 0.0 & 0.0 & 0.0 & 0.0 & 0.0 \\
\hline & & DEN & 0.0 & 0.0 & 0.0 & 0.0 & 0.0 & 0.483685 & $-0.288 \mathrm{E}-7$ & 3.04067 & 0.0 & 0.0 & 0.0 & 0.0 \\
\hline & & 3 DM & 0.0 & 0.0 & 0.0 & 0.0 & 0.0 & 0.0 & 0.0 & 0.0 & 0.0 & 0.0 & 16.20219 & 0.0 \\
\hline & & DCARGR-TS & $-0.171 \mathrm{E}-8$ & 0.0 & -22.523 & -67875.2 & 0.0 & 109051.2 & 0.0 & -0.080657 & $-0.791 \mathrm{E}-8$ & 0.411475 & 0.0516349 & 0.0 \\
\hline & & DCARHC & $-0.325 \mathrm{E}-8$ & 0.0 & $0.141 \mathrm{E}-8$ & 167600.4 & 0.0 & 8.871403 & 0.0 & -0.016989 & $-0.707 \mathrm{E}-7$ & 1.382778 & $0.262 \mathrm{E}-8$ & 0.0 \\
\hline \multirow{14}{*}{$\overrightarrow{\vec{c}}$} & \multirow{4}{*}{ Div. 1} & DW & 0.0 & 0.0 & 0.0 & 0.0 & 0.0 & 0.0 & 0.0 & 0.0 & 0.0 & 0.0 & 0.0 & 0.0 \\
\hline & & 1 DEN & 0.0 & 0.0 & 0.0 & 0.0 & 0.0 & 0.0 & 0.0 & 0.0 & 0.0 & 5.39747 & 0.0 & 0.0 \\
\hline & & DCARGR-TS & 0.0 & 0.0 & 968808.1 & -2660908 & $-0.795 \mathrm{E}-7$ & 80279.25 & 0.0 & -0.214151 & $-0.932 \mathrm{E}-6$ & 2077114 & 300000 & 0.0 \\
\hline & & DCARHC & 0.0 & 0.0 & $0.137 \mathrm{E}-8$ & 0.0 & $0.108 \mathrm{E}-6$ & 2264.724 & 0.0 & $0.141 \mathrm{E}-8$ & $-0.109 \mathrm{E}-5$ & $0.345 \mathrm{E}-8$ & 0.0 & 0.0 \\
\hline & \multirow{5}{*}{ Div. 2} & DW & 0.0 & 0.0 & 0.0 & 0.0 & 0.0 & 392.8517 & 0.0 & 0.0 & 0.0 & 0.0 & 0.0 & 0.0 \\
\hline & & DEN & 0.0 & 0.0 & 0.0 & 0.0 & 0.0 & 186.9409 & 0.0 & 0.0039664 & 0.0 & 0.0 & 0.0 & 0.0 \\
\hline & & $2 \mathrm{DM}$ & 0.0 & 0.0 & 0.0 & 0.0 & 0.0 & 0.0 & 0.0 & 0.0 & 0.0 & 0.0 & 0.0 & 0.0 \\
\hline & & DCARGR-TS & 0.0 & 0.0 & 1314663.0 & -260899.8 & 0.0 & 120860.2 & 0.0 & -0.299907 & 0.0 & 1720426 . & 399993.9 & 0.0 \\
\hline & & DCARHC & 0.0 & 0.0 & 8.57366 & 3836057.0 & $0.186 \mathrm{E}-8$ & $-0.186 \mathrm{E}-8$ & 0.0 & -0.492839 & 0.0 & -12.7082 & 0.210135 & 0.0 \\
\hline & & DW & 0.0 & 0.0 & 0.0 & 0.0 & 0.0 & 0.0 & 0.0 & 0.0 & 0.0 & 0.0 & 114.9616 & 0.0 \\
\hline & & DEN & 0.0 & 0.0 & 30.8368 & 0.0 & 0.0 & 0.0 & 0.0 & 0.0 & 0.0 & 4.033516 & 6.212341 & 0.0 \\
\hline & Div. 3 & $3 \mathrm{DM}$ & 0.0 & 0.0 & 0.0 & 0.0 & 0.0 & 0.0 & 0.0 & 0.0 & 0.0 & 0.0 & 0.0 & 0.0 \\
\hline & & DCARGR-TS & 0.0 & 0.0 & 985936.7 & -200734.2 & 0.0 & 90172.23 & 0.0 & -0.177334 & $0.186 \mathrm{E}-8$ & 1575897. & 299999.8 & 0.0 \\
\hline & & DCARHC & 0.0 & 0.0 & $0.321 \mathrm{E}-7$ & 3833079.0 & $0.175 \mathrm{E}-8$ & 202.8921 & 0.0 & -0.388562 & $-0.170 \mathrm{E}-5$ & 31.62460 & $0.0139 \mathrm{E}-8$ & 0.0 \\
\hline \multirow{14}{*}{ 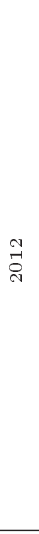 } & \multirow{4}{*}{ Div. 1} & DW & 0.0 & 0.0 & 77.5122 & 0.0 & 0.0 & 0.0 & 0.0 & 0.0 & 0.0 & 0.0 & 28.28630 & 0.0 \\
\hline & & $1 \quad \mathrm{DEN}$ & 0.0 & 0.0 & 0.0 & 0.0 & 0.0 & 0.0 & 0.0 & 0.0 & 0.0 & 0.0 & 0.937587 & 0.0 \\
\hline & & DCARGR-TS & 0.0 & 0.0 & 388879.6 & -1068089 & $-0.313 \mathrm{E}-7$ & 32224.09 & 0.0 & -0.085960 & $-0.373 \mathrm{E}-6$ & 833753.7 & 120420.0 & 0.0 \\
\hline & & DCARHC & 0.0 & 0.0 & 0.0 & $-0.372 \mathrm{E}-8$ & $0.512 \mathrm{E}-8$ & 110.0272 & 0.0 & 0.0 & $-0.886 \mathrm{E}-6$ & 0.0 & 0.0 & 0.0 \\
\hline & \multirow{5}{*}{ Div. 2} & DW & 0.0 & 141.0 & 0.0 & 0.0 & 0.0 & 249.0799 & 0.0 & $-0.302 \mathrm{E}-7$ & 0.0 & 0.0 & 0.0 & 0.0 \\
\hline & & DEN & 0.0 & 0.0 & 24.7075 & 0.0 & 0.0 & 0.0 & 0.0 & $-0.302 \mathrm{E}-7$ & 0.0 & 0.0 & 0.0 & 0.0 \\
\hline & & $2 \mathrm{DM}$ & 0.0 & 0.0 & 0.0 & 0.0 & 0.0 & 0.0 & 0.0 & $-0.302 \mathrm{E}-7$ & 0.0 & 0.0 & 433.8932 & 0.0 \\
\hline & & DCARGR-TS & 0.0 & 0.0 & 527413.5 & -105153.8 & 0.0 & 48003.31 & 0.0 & -0.120356 & 0.0 & 691015.0 & 159997.6 & 0.0 \\
\hline & & DCARHC & 0.0 & 0.0 & 0.41653 & 186367.3 & 0.0 & 0.0 & 0.0 & -0.402053 & 0.0 & -0.617406 & 0.010209 & 0.0 \\
\hline & \multirow{5}{*}{ Div. 3} & DW & 0.0 & 0.0 & 519.468 & 0.0 & 0.0 & 0.0 & $-0.298 \mathrm{E}-7$ & $-0.238 \mathrm{E}-7$ & 0.0 & 0.0 & 58.75217 & 0.0 \\
\hline & & DEN & 0.0 & 0.0 & 17.9930 & 0.0 & 0.0 & 0.0 & 0.0 & $-0.238 \mathrm{E}-7$ & 0.0 & 0.0 & 5.812746 & 0.0 \\
\hline & & $3 \mathrm{DM}$ & 0.0 & 0.0 & 0.0 & 0.0 & 0.0 & 0.0 & $-0.372 \mathrm{E}-8$ & $-0.238 \mathrm{E}-7$ & 0.0 & 0.0 & 3.681721 & 0.0 \\
\hline & & DCARGR-TS & 0.0 & 0.0 & 395664.7 & -80762.99 & 0.0 & 36253.35 & 0.0 & -0.071172 & 0.0 & 632986.4 & 120999.9 & 0.0 \\
\hline & & DCARHC & 0.0 & $-0.158 \mathrm{E}-8$ & $0.242 \mathrm{E}-7$ & 186222.6 & 0.0 & 9.857115 & 0.0 & -0.316984 & $0.208 \mathrm{E}-8$ & 1.536419 & 0.0 & 0.0 \\
\hline & & DW & 0.0 & 0.0 & 0.0 & 0.0 & 0.0 & 0.0 & 0.0 & 0.0 & 0.0 & 0.0 & 0.0 & 0.0 \\
\hline & Div. 1 & 1 DEN & 0.0 & 0.0 & 0.0 & 0.0 & 0.0 & 0.0 & 0.0 & 0.0 & 0.0 & 0.0 & 0.0 & 0.0 \\
\hline & & DCARGR-TS & 0.0 & $0.185 \mathrm{E}-8$ & 121642.0 & -281791.8 & -202600.0 & -418299.0 & 0.0 & 0.0428301 & $-0.212 \mathrm{E}-6$ & 0.0077834 & 60000.0 & 0.0 \\
\hline & & DCARHC & 0.0 & $-0.276 \mathrm{E}-8$ & $-0.110 \mathrm{E}-8$ & $-0.372 \mathrm{E}-8$ & $0.558 \mathrm{E}-8$ & 110.0272 & 0.0 & 0.0 & $-0.886 \mathrm{E}-6$ & $0.149 \mathrm{E}-8$ & 0.0 & 0.0 \\
\hline & & DW & 0.0 & 0.0 & 0.0 & 0.0 & 0.0 & 0.0 & 0.0 & $0.2491 \mathrm{E}-4$ & 0.0 & 0.0 & 0.0 & 0.0 \\
\hline & & DEN & 0.0 & 0.0 & 0.0 & 0.0 & 0.0 & 0.0 & 0.0 & $0.1992 \mathrm{E}-4$ & 0.0 & 0.0 & 0.0 & 0.0 \\
\hline$\stackrel{m}{=}$ & Div. 2 & $2 \mathrm{DM}$ & 0.0 & 0.0 & 0.0 & 0.0 & 0.0 & 0.0 & 0.0 & $0.1973 \mathrm{E}-5$ & 0.0 & 0.0 & $-0.023 \mathrm{E}-8$ & 0.0 \\
\hline$\stackrel{4}{4}$ & & DCARGR-TS & $-0.186 \mathrm{E}-8$ & $-0.341 \mathrm{E}-7$ & 270268.8 & 106528.3 & 0.0 & -130917.9 & 0.0 & -0.604637 & 0.0 & 0.0679126 & 79998.78 & 0.0 \\
\hline & & DCARHC & $-0.372 \mathrm{E}-8$ & $0.608 \mathrm{E}-8$ & 0.41653 & 186367.3 & 0.0 & 0.00 & 0.0 & -0.402053 & 0.0 & -0.617406 & 0.010209 & 0.0 \\
\hline & & DW & 0.0 & 0.0 & 0.0 & 0.0 & 0.0 & 0.0 & 0.0 & $0.684 \mathrm{E}-7$ & 0.0 & 0.0 & 0.0 & 0.0 \\
\hline & & DEN & 0.0 & 0.0 & 0.0 & 14.005 & 0.0 & 0.0 & 0.0 & 0.0 & 0.0 & 8.883 & 0.0 & 0.0 \\
\hline & Div. 3 & 3 DM & 0.0 & 0.0 & 0.0 & 0.0 & 0.0 & 0.0 & 0.0 & 0.0 & 0.0 & 0.0 & 0.0 & 0.0 \\
\hline & & DCARGR-TS & $-0.643 \mathrm{E}-8$ & 0.0 & 202841.0 & 78873.71 & 0.0 & -186631.4 & 0.0 & -0.035753 & 0.0 & 0.2064502 & 59999.96 & 0.0 \\
\hline & & DCARHC & $-0.340 \mathrm{E}-7$ & $-0.186 \mathrm{E}-8$ & 0.0 & 186222.6 & 0.0 & 9.857115 & 0.0 & -0.316984 & 0.0 & 1.536419 & 0.0 & 0.0 \\
\hline
\end{tabular}

1. DW and DEN denote changes of wage and energy costs; 2. DCARGR-TS denotes changes of green programs and ISO TS investments;

3. DCARHC denotes changes of human care programs costs; 4. DM represents changes of material costs. 
Table 8. Results of Model (31) (continued).

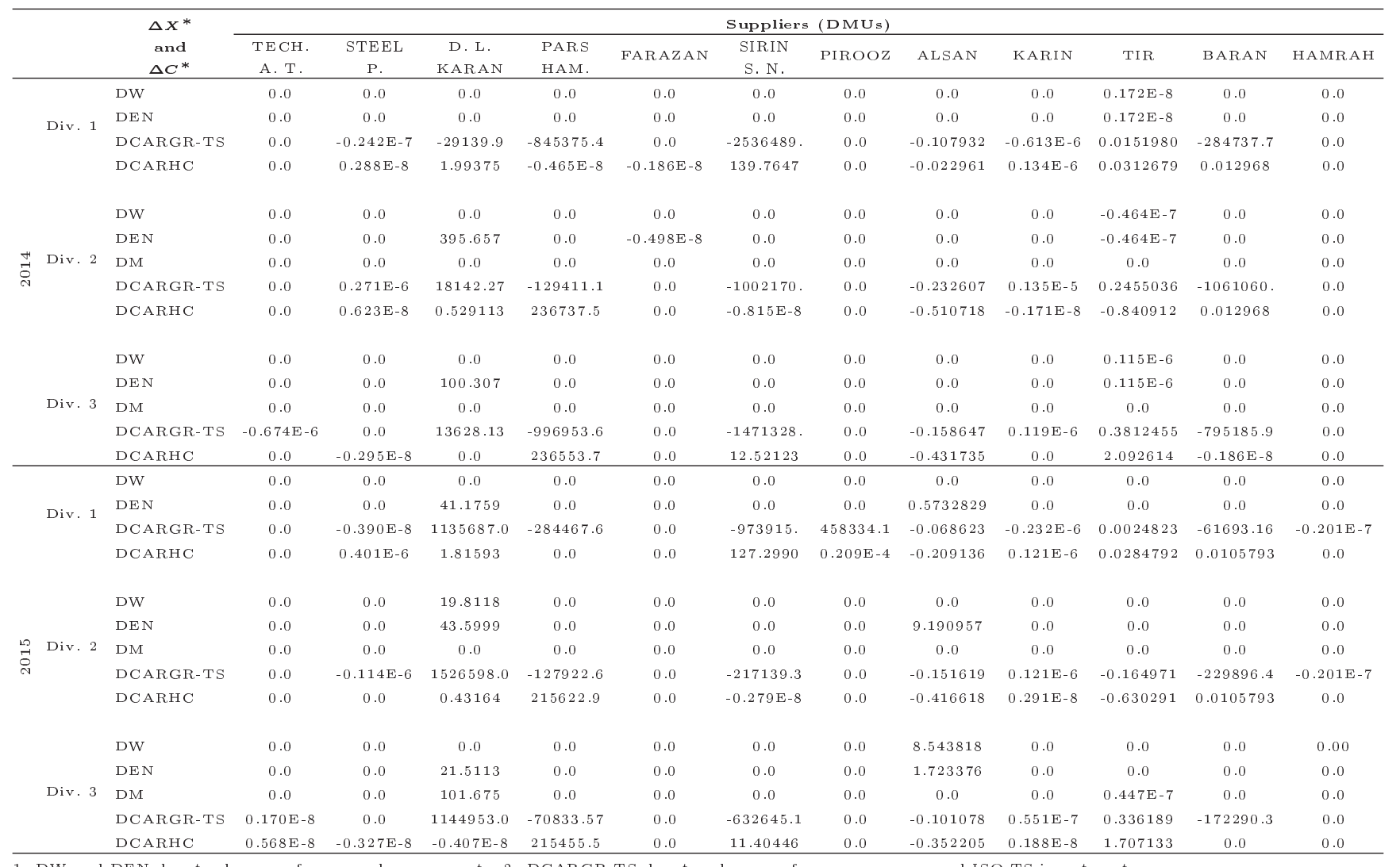

1. DW and DEN denote changes of wage and energy costs; 2 . DCARGR-TS denotes changes of green pro
3. DCARHC denotes changes of human care programs costs; 4 . DM represents changes of material costs.

lower bounds and be increased to their upper bounds. In the first approach, inputs cannot decrease to less than their current values. Negative or positive changes in inputs/outputs demonstrate the direction of future investments. This paper assessed sustainability of supply chains. For prospective researchers, we suggest running our model in fields of assessing production lines, assessing electricity transfer lines, etc.

\section{Acknowledgments}

Authors would like to appreciate constructive comments of Editor-in-Chief and two anonymous Reviewers.

\section{References}

1. Mentzer, J.T., DeWitt, W., Keebler, J.S., Min, S., Nix, N.W., Smith, C.D., and Zacharia, Z.G. "Defining supply chain management", Journal of Business logistics, 22(2), pp. 1-25 (2002).

2. Drumwright, M.E. "Socially responsible organizational buying: Environmental concern as a non-economic buying criterion", Journal of Marketing, 58(3), pp. 119 (1994).

3. Murphy, P.R., Poist, R.F., and Braunschweig, C.D.
"Management of environmental issues in logistics: Current status and future potential", Transportation Journal, 34(1), pp. 48-56 (1994).

4. Carter, C.R. and Rogers, D.S. "A framework of sustainable supply chain management: moving toward new theory", International Journal of Physical Distribution and Logistics Management, 38(5), pp. 360-387 (2008).

5. Seuring, S.A. "Review of modeling approaches for sustainable supply chain management", Decision Support Systems, 54(4), pp. 1513-1520 (2013).

6. Tseng, M.L., Divinagracia, L., and Divinagracia, R. "Evaluating firm's sustainable production indicators in uncertainty", Computers \& Industrial Engineering, 57(4), pp. 1393-1403 (2009).

7. Tseng, M.L. "Using a hybrid MCDM model to evaluate firm environmental knowledge management in uncertainty", Applied Soft Computing, 11(1), pp. 1340-1352 (2010).

8. Tseng, M.L. and Chiu, A.S. "Evaluating firm's green supply chain management in linguistic preferences", Journal of Cleaner Production, 40, pp. 22-31 (2013).

9. Charnes, A., Cooper, W.W., and Rhodes, E. "Measuring the efficiency of decision making units", European Journal of Operational Research, 2(6), pp. 429-444 (1978). 
10. Kumar, A., Jain, V., and Kumar, S. "Comprehensive environment friendly approach for supplier selection", Omega, 42(1), pp. 109-123 (2014).

11. Lewis, H.F. and Sexton, T.R. "Network DEA: Efficiency analysis of organizations with complex internal structure", Computers \& Operations Research, 31(9), pp. 1365-1410 (2004).

12. Färe, R. and Grosskopf, S. "Intertemporal production frontiers: with dynamic DEA", Journal of the Operational Research Society, 48(6), pp. 656-656 (1997).

13. Tone, K. and Tsutsui, M. "Dynamic DEA with network structure: A slacks-based measure approach", Omega, 42(1), pp. 124-131 (2014).

14. Bowen, F.E., Cousins, P.D., Lamming, R.C., and Faruk, A.C. "The role of supply management capabilities in green supply", Production and Operations Management, 10(2), pp. 174-189 (2001).

15. Pesonen, H.L. "Environmental management of value chains", Greener Management International, 33, pp. 45-58 (2001).

16. Seuring, S.A. "Green supply chain costing: joint cost management in the polyester linings supply chain", Greener Management International, pp. 71-80, Spring (2001).

17. Bose, I. and Pal, R. "Do green supply chain management initiatives impact stock prices of firms?", Decision Support Systems, 52(3), pp. 624-634 (2012).

18. Srivastava, S.K. "Green supply-chain management: A state-of-the-art literature review", International Journal of Management Review, 9(1), pp. 53-80 (2007).

19. Liu, Z.L., Anderson, T.D., and Cruz, J.M. "Consumer environmental awareness and competition in two-stage supply chains", European Journal of Operational Research, $218(3)$, pp. 602-613 (2012).

20. Zhang, L., Wang. J., and You. J. "Consumer environmental awareness and channel coordination with two substitutable products", European Journal of Operational Research, 241(1), pp. 63-73 (2015).

21. Ghosh, D. and Shah, J. "Supply chain analysis under green sensitive consumer demand and cost sharing contract", International Journal of Production Economics, 164, pp. 319-329 (2015).

22. Xie, G. "Modeling decision processes of a green supply chain with regulation on energy saving level", Computers \& Operations Research, 54, pp. 266-273 (2015).

23. Genovese, A., Acquaye, A.A., Figueroa, A., and Koh, S.L. "Sustainable supply chain management and the transition towards a circular economy: Evidence and some applications", Omega, 66, pp. 344-357 (2017).

24. Su, C.M., Horng, D.J., Tseng, M.L., Chiu, A.S., Wu, K.J., and Chen, H.P. "Improving sustainable supply chain management using a novel hierarchical greyDEMATEL approach", Journal of Cleaner Production, 134, pp. 469-481(2016).
25. Dubey, R., Gunasekaran, A., Papadopoulos, T., Childe, S.J., Shibin, K.T., and Wamba, S.F. "Sustainable supply chain management: framework and further research directions", Journal of Cleaner Production, 142, pp. 1119-1130 (2017).

26. Kumar, D., Rahman, Z., and Chan, F.T. "A fuzzy AHP and fuzzy multi-objective linear programming model for order allocation in a sustainable supply chain: A case study", International Journal of Computer Integrated Manufacturing, 30(6), pp. 535-551 (2017).

27. Azadi, M., Jafarian, M., Farzipoor Saen, R., and Mirhedayatian, S.M. "A new fuzzy DEA model for evaluation of efficiency and effectiveness of suppliers in sustainable supply chain management context", Computers \& Operations Research, 54, pp. 274-285 (2015).

28. Li, Y. and Cui, Q. "Carbon neutral growth from 2020 strategy and airline environmental inefficiency: A network range adjusted environmental data envelopment analysis", Applied Energy, 199, pp. 13-24 (2017).

29. Awasthi, A., Chauhan, S.S., and Goyal, S.K. "A fuzzy multicriteria approach for evaluating environmental performance of suppliers", International Journal of Production Economics, 126(2), pp. 370-378 (2010).

30. Büyüközkan, G. and Çifçi, G. "A novel fuzzy multicriteria decision framework for sustainable supplier selection with incomplete information", Computers in Industry, 62(2), pp. 164-174 (2011).

31. Erol, I., Sencer, S., and Sari, R. "A new fuzzy multi-criteria framework for measuring sustainability performance of a supply chain", Ecological Economics, 70(6), pp. 1088-1100 (2011).

32. Govindan, K., Khodaverdi, R., and Jafarian, A. "A fuzzy multi criteria approach for measuring sustainability performance of a supplier based on triple bottom line approach", Journal of Cleaner Production, 47, pp. 345-354 (2013).

33. Kuo, R.J., Wang, Y.C., and Tien, F.C. "Integration of artificial neural network and MADA methods for green supplier selection", Journal of Cleaner Production, 18(12), pp. 1161-1170 (2010).

34. Punniyamoorthy, M., Mathiyalagan, P., and Parthiban, P. "A strategic model using structural equation modeling and fuzzy logic in supplier selection", Expert Systems with Applications, 38(1), pp. $458-474$ (2011).

35. Amindoust, A., Ahmed, S., Saghafinia, A. and Bahreininejad, A. "Sustainable supplier selection: A ranking model based on fuzzy inference system", $A p$ plied Soft Computing, 12(6), pp. 1668-1677 (2012).

36. Yeh, W.C. and Chuang, M.C. "Using multi-objective genetic algorithm for partner selection in green supply chain problems", Expert Systems with Applications, 38(4), pp. 4244-4253 (2011). 
37. Wei, Q., Zhang, J., and Zhang, X. "Theory and methodology. An inverse DEA model for inputs/outputs estimate", European Journal of Operational Research, 121(1), pp. 151-163 (2000).

38. Yan, H., Wei, Q., and Hao, G. "DEA models for resource reallocation and production input/output estimation", European Journal of Operational Research, 136(1), pp. 19-31 (2002).

39. Jahanshahloo, G.R., Lotfi, F.H., Shoja, N., Tohidi, G., and Razavyan, S. "The outputs estimation of a DMU according to improvement of its efficiency", Applied Mathematics and Computation, 147(2), pp. 409-413 (2004).

40. Jahanshahloo, G.R., Lotfi, F.H., Shoja, N., Tohidi, G., and Razavyan, S. "Input estimation and identification of extra inputs in inverse DEA models", Applied Mathematics and Computation, 156(2), pp. 427-437 (2004).

41. Jahanshahloo, G.R., Lotfi, F.H., Shoja, N., Tohidi, G., and Razavyan, S. "Sensitivity of efficiency classifications in the inverse DEA models", Applied Mathematics and Computation, 169(2), pp. 905-916 (2005).

42. Jahanshahloo, G.R., Soleimani-Damaneh, M., and Ghobadi, S. "Inverse DEA under inter-temporal dependence using multiple-objective programming", European Journal of Operational Research, 240(2), pp. 447-456 (2015).

43. Lertworasirikul, S., Charnsethikul, P., and Fang, S.C. "Inverse data envelopment analysis model to preserve relative efficiency values: The case of variable returns to scale", Computers \& Industrial Engineering, 61(4), pp. 1017-1023 (2011).

44. Banker, R.D., Charnes, A., and Cooper, W.W. "Some models for estimating technical and scale inefficiencies in data envelopment analysis", Management Science, 30(9), pp. 1078-1092 (1984).

45. Amin, G.R., Emrouznejad, A., and Gattoufi, S. "Minor and major consolidations in inverse DEA: Definition and determination", Computers \& Industrial Engineering, 103, pp. 193-200 (2017).

46. Amin, G.R., Emrouznejad, A., and Gattoufi, S. "Modelling generalized firms' restructuring using inverse DEA", Journal of Productivity Analysis, 48(1), pp. 5161 (2017).

47. Eyni, M., Tohidi, G., and Mehrabeian, S. "Applying inverse DEA and cone constraint to sensitivity analysis of DMUs with undesirable inputs and outputs", Journal of the Operational Research Society, 68(1), pp. 34-40 (2016).

48. Lovell, C.K. and Pastor, J.T. "Units invariant and translation invariant DEA models", Operations Research Letters, 18(3), pp. 147-151 (1995).
49. Pastor, J.T. and Ruiz, J.L. "Variables with negative values in DEA", In Modeling Data Irregularities and Structural Complexities in Data Envelopment Analysis, Springer, USA, pp. 63-84 (2007).

50. Pastor, J.T. "Translation invariance in data envelopment analysis: A generalization", Annals of Operations Research, 66(2), pp. 93-102 (1996).

51. Cooper, W.W., Seiford, L., and Tone, K., Data envelopment Analysis: A Comprehensive Text with Models, Applications, References and DEA-Solver Software, Springer, p. 490 (2007).

52. Cooper, W.W., Park, K.S., and Pastor, J.T. "RAM: A range adjusted measure of inefficiency for use with additive models, and relations to other models and measures in DEA", Journal of Productivity Analysis, 11(1), pp. 5-42 (1999).

53. Tone, K. and Tsutsui, M. "Network DEA: a slacksbased measure approach", European Journal of Operational Research, 197(1), pp. 243-252 (2009).

54. Färe, R. and Grosskopf, S. "Productivity and intermediate products: A frontier approach", Economics Letters, 50(1), pp. 65-70 (1996).

55. Färe, R. and Grosskopf, S. "Network DEA", SocioEconomic Planning Sciences, 34(1), pp. 35-49 (2000).

56. Sexton, T.R. and Lewis, H.F. "Two-stage DEA: An application to major league baseball", Journal of Productivity Analysis, 19(2-3), pp. 227-249 (2003).

57. Mirhedayatian, S.M., Azadi, M., and Farzipoor Saen, R. "A novel network data envelopment analysis model for evaluating green supply chain management", International Journal of Production Economics, 147, pp. 544-554 (2014).

58. Tone, K. and Tsutsui, M. "Dynamic DEA: A slacksbased measure approach", Omega, 38(3), pp. 145-156 (2010).

59. Chen, C.M. "A network-DEA model with new efficiency measures to incorporate the dynamic effect in production networks", European Journal of Operational Research, 194(3), pp. 687-699 (2009).

60. Park, K.S. and Park, K. "Measurement of multiperiod aggregative efficiency", European Journal of Operational Research, 193(2), pp. 567-580 (2009).

61. Shabanpour, H., Yousefi, S., and Saen, R.F. "Forecasting efficiency of green suppliers by dynamic data envelopment analysis and artificial neural networks", Journal of Cleaner Production, 142, pp. 1098-1107 (2017).

62. Aida, K., Cooper, W.W., Pastor, J.T., and Sueyoshi, T. "Evaluating water supply services in Japan with RAM: A range-adjusted measure of inefficiency", Omega, 26(2), pp. 207-232 (1998). 
63. Cooper, W.W., Pastor, J.T., Borras, F., Aparicio, J., and Pastor, D. "BAM: A bounded adjusted measure of efficiency for use with bounded additive models", Journal of Productivity Analysis, 35(2), pp. 85-94 (2011).

64. Hillier, F.S. and Lieberman, G.J., Introduction to Operations Research, McGraw Hill, New York (2001).

65. Seuring, S. and Müller, M. "Core issues in sustainable supply chain management-a Delphi study", Business Strategy and the Environment, 17(8), pp. 455-466 (2008).

66. Carbone, V., Moatti, V., and Wood, C.H. "Diffusion of sustainable supply chain management: Toward a conceptual framework", In Supply Chain Forum: An International Journal, Taylor \& Francis, 13(4), pp. 2639 (2012).

67. Wittstruck, D. and Teuteberg, F. "Understanding the success factors of sustainable supply chain management: empirical evidence from the electrics and electronics industry", Corporate Social Responsibility and Environmental Management, 19(3), pp. 141-158 (2012).

68. Li, H. "Evaluation index system and evaluation method for sustainable development of industrial park", In Informatics and Management Science, VI, Springer, London, pp. 199-207 (2013).

\section{Biographies}

Majid Kalantary received his BS degree from the Department of Industrial Management at Islamic Azad
University, Karaj, Iran. He obtained his MS degree in Industrial Management from Tehran University, Tehran, Iran. He is currently a PhD candidate of Industrial Management at Islamic Azad University, Science and Research Branch, Tehran, Iran. He is a sessional lecturer of the Department of Industrial Management at Islamic Azad University, Karaj Branch, Karaj, Iran. His research interests include data envelopment analysis and multi-criteria decision making.

Reza Farzipoor Saen is a Full Professor of Operations Management at the Department of Industrial Management, Islamic Azad University, Karaj Branch in Iran. Also, he is a Visiting Professor at Nottingham Trent University in UK. Furthermore, he is an Adjunct Professor in Maastricht School of Management in Netherlands. In 2002, he obtained his PhD in Industrial Management from the Islamic Azad University, Science and Research Branch in Iran. He has published over 168 refereed papers in many prestigious journals.

Abbas Toloie Eshlaghy is a Full Professor of Industrial Management at the Department of Industrial Management, Science and Research Branch, Islamic Azad University, Tehran, Iran. Also, he is the Head of Industrial Management Department in Science and Research Branch, Islamic Azad University in Iran. He obtained his $\mathrm{PhD}$ in Industrial Management from the Islamic Azad University, Science and Research Branch in Iran. He has published over 97 refereed papers in many journals. 